Printed

RFP-4162

September 12, 1988

UC-25 MATERIALS

DOE/OSTI-4500 (Rev. 73)

REP -4162

DE89 002541

\title{
A SUMMARY OF SPECIAL COATINGS PROJECTS CONDUCTED IN SUPPORT OF THE DIE CASTING PROGRAM
}

\author{
J. E. Selle
}

R. L. Thomas, Editor

I. C. Delaney, Compositor

This report was prepared as an account of work sponsored by an agency of the United States Government Neither the United States Government nor any agency thereof, nor any of their employees, makes any warranty, express or mplied, or assumes any legal liabihty or responsibility for the accuracy, completeness, or usefulness of any information, apparatus, product, or process disclosed, or represents that its use would not infringe privately owned rights Reference herein to any specific commercial product, process, or service by trade name, trademark, manufacturer, or otherwise does not necessarily constitute or imply its endorsement, recommendation, or favoring by the United States Government or any agency thereof. The views and opinions of authors expressed herein do not necessarly state or reflect those of the United States Government or any agency thereof.

\author{
ROCKWELL INTERNATIONAL \\ AEROSPACE OPERATIONS \\ ROCKY FLATS PLANT \\ P. O. BOX 464 \\ GOLDEN, COLORADO 80402-0464
}

Prepared under Contract DE-AC04-76DPO3533

for the

Albuquerque Operations Office

U.S. Department of Energy

\section{Ceramies}

Coatings

Die Casting

Erbium Oxide

Heat Transfer

Plutonium

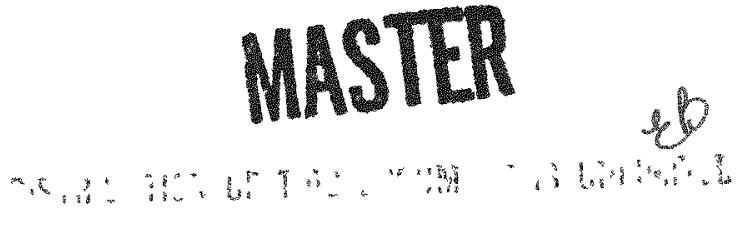




\section{DISCLAIMER}

This report was prepared as an account of work sponsored by an agency of the United States Government. Neither the United States Government nor any agency Thereof, nor any of their employees, makes any warranty, express or implied, or assumes any legal liability or responsibility for the accuracy, completeness, or usefulness of any information, apparatus, product, or process disclosed, or represents that its use would not infringe privately owned rights. Reference herein to any specific commercial product, process, or service by trade name, trademark, manufacturer, or otherwise does not necessarily constitute or imply its endorsement, recommendation, or favoring by the United States Government or any agency thereof. The views and opinions of authors expressed herein do not necessarily state or reflect those of the United States Government or any agency thereof. 


\section{DISCLAIMER}

Portions of this document may be illegible in electronic image products. Images are produced from the best available original document. 
RFP-4162 


\section{CONTENTS}

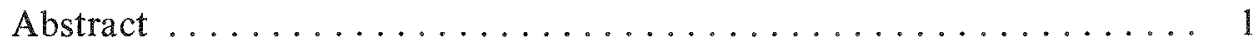

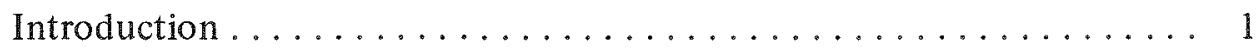

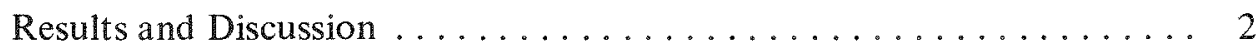

Calculations. ......................... 2

Effect of Surface Roughness on Fluid Flow .......... 2

Conductance as a Function of Coating Thickness ........ 3

Conductivity of Coatings as a Function of Porosity ...... . 5

Solidification of Microspheres. . . . . . . . . . . . 6

Effect of Insulating Coatings. . . . . . . . . 8

Remelting of Microspheres .................. 8

Experimental Work ....................... 10

Comparative Insulating Value of Coatings. . . . . . . 10

Plasma-Sprayed Coatings. . . . . . . . . . . . 17

Low-Density Coatings . . . . . . . . . . . . 17

Release Coatings ....................... 19

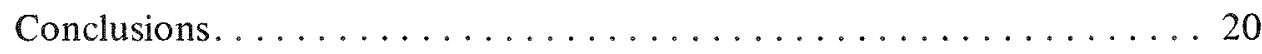

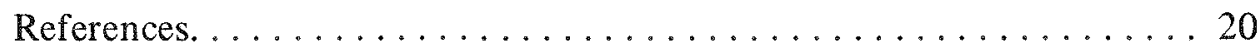


RFP- 4162

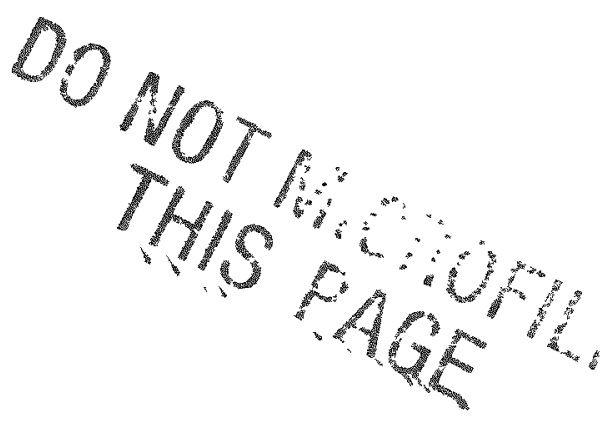




\title{
A SUMMARY OF SPECIAL COATINGS PROJECTS CONDUCTED IN SUPPORT OF THE DIE CASTING PROGRAM
}

\author{
J. E. Selle
}

\section{ABSTRACT}

The usefulness of various kinds of coatings to the die casting program has been studied. This work includes heat transfer and fluid flow calculations, as well as experimental work, to ex amine the feasibility and characteristics of various types of coatings. Calculations include the effect of surface roughness on fluid flow, conductance as a function of coating thickness, conductivity as a function of coating porosity, and solidification and possible remelting of microspheres of metal. In each case, the model is described and the results are presented. Experimental work involved evaluating the relative insulating value of various coatings and an analysis of commercial flame-sprayed coatings, low-density coatings, and release coatings. In each case, description of the experimental arrangement is given and the results are described.

\section{INTRODUCTION}

The purpose of the Die Casting Program is to investigate the feasibility of producing shaped parts by the die casting process. Success of this program depends, in part, on the proper distribution and control of the temperature at various points within the system. In a system as complex as a die casting machine, heat transfer and temperature control can take many forms. The production of sound, defectfree castings with metallurgical properties such as grain size and density is, in part, critically dependent on proper temperature control.

A cold shut is one of the more common defects found in die castings. These defects are an indication of too rapid solidification of the metal during filling of the die cavity. Prevention depends on the proper filling and control of the heat losses so that the cavity is filled before any metal solidifies. If heat losses from the molten metal are too high, some of the metal can solidify before the die cavity is filled. Molten metal adjacent to the solidified area will solidify independently, causing a defect (cold shut) between the two regions.

Control of the grain size is also of critical importance. The grain size is an inverse function of cooling rate through the two-phase delta-plusepsilon range of $575-475^{\circ} \mathrm{C}$. Homogenization time is a function of grain size as shown in Figure $1 .^{1}$ As the cooling rate increases, the grain size decreases, as does the homogenization time. A grain size less than 10-12 $\mu \mathrm{m}$ is required to produce an acceptable homogenization time less than 8 hours.

Heat loss from the casting can be controlled by changing the die temperature. Increasing the die temperature decreases the rate of heat loss to the die. However, there are two disadvantages to reducing the heat loss rate by this method. Die temperature can become too high so that deterioration of the die material can occur. Also, if the die temperature is above the critical transformation temperature range, the cooling rate will be too

FIGURE 1. Relation Between Grain Size and Anneal Time Required for Homogenization in a Cored Pu-1.0 wt \% Ga Delta Stabilized Alloy

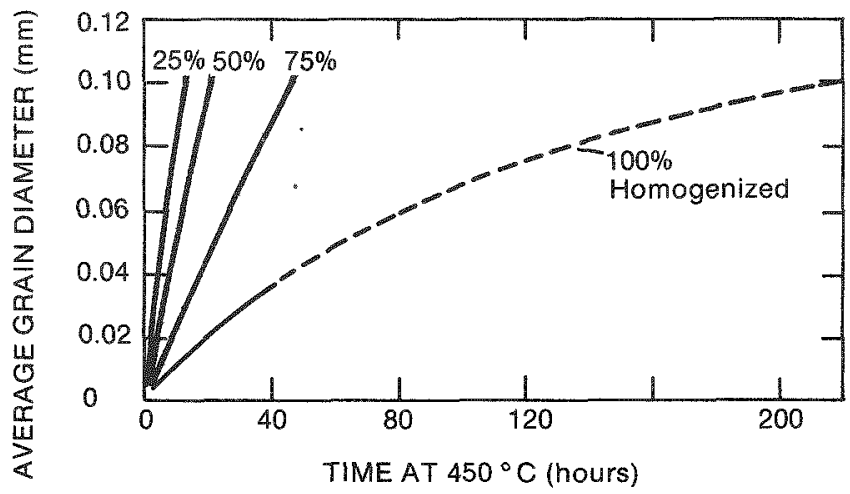


slow, resulting in a large grain size, which in turn increases the homogenization time.

For a system as massive as a die casting die, relative to the amount of metal (heat content) being cast, the cooling rate is constant for a given die temperature regardless of heat input by the liquid. Therefore, the casting cooling rate through the critical transformation temperature cannot be controlled by the metal temperature at the time of casting. It then becomes necessary to control the grain size by decreasing the die temperature below the critical transformation temperature range of $575-475^{\circ} \mathrm{C}$.

The original side-feed die design was such that die temperatures of $500-600^{\circ} \mathrm{C}$ were used to minimize cold shutting. This produced grain sizes of the order of 35-40 $\mu \mathrm{m}$. Since this was too large for rapid homogenization, a method to reduce the die temperature while preventing cold shutting was necessary. Application of a ceramic insulating coating on the die to retard short-term heat losses was proposed. An insulating coating would provide a steep temperature gradient across the molten metal-die interface compared to a noninsulating coating, despite the fact that the die temperature is lower. Once the die cavity is filled properly, the coating's insulating value is no longer needed, and rapid cooling then becomes of primary interest to produce a fine grained structure. At this point, the large mass of the die at a much lower temperature absorbs heat from the casting faster than that obtained with a high-temperature die. However, if the coating is too thick, the casting cools too slowly. Calculations by P. Burgardt at Rocky Flats indicate that a coating about 0.020 inch of theoretically dense $\mathrm{ZrO}_{2}$, with a thermal conductivity of $0.0045 \mathrm{cal} / \mathrm{sec}-\mathrm{cm}-{ }^{\circ} \mathrm{C}$, will be satisfactory.

Numerous questions were raised as a result of this proposal to use an insulating coating. Several small projects were initiated to address these questions and develop the concept of using insulating coating in the die casting process. Some of these projects involved heat transfer calculations, while others were experimental in nature. This report presents the results of these projects. Since they are somewhat diverse in nature, each project is discussed separately.
Included in this report are:

\section{Calculations}

1. Effect of surface roughness on fluid flow.

2. Conductance as a function of coating thickness.

3. Conductivity of coating material as a function of porosity.

4. Solidification of microspheres (cold shots).

5. Remelting of microspheres (cold shots).

Experimental Work

1. Comparative insulating value of coatings.

2. Flame-sprayed coatings.

3. Low-density coatings.

4. Release coatings.

\section{RESULTS AND DISCUSSION}

\section{Calculations}

\section{Effect of Surface Roughness on Fluid Flow}

Concerns were expressed that the roughness of a sprayed coating would retard metal flow. Therefore, calculations were performed to address the question.

Surface roughness has an effect on the friction factor associated with fluid flow, which in turn influences the average velocity $(\bar{V})$ of the fluid according to the relationship: ${ }^{2}$

$$
\bar{V}^{2}=\left(\frac{1}{2 \mathrm{f}}\right)\left(\frac{\mathrm{D}}{\mathrm{L}}\right)\left(\frac{\Delta \mathrm{P}}{\rho}\right)
$$

Where: $f=$ friction factor

$$
\mathrm{D}=\text { diameter of the tube }
$$

$\mathrm{L}=$ length of the tube

$\Delta \mathrm{P}=$ pressure drop

$\rho=$ density of the liquid 


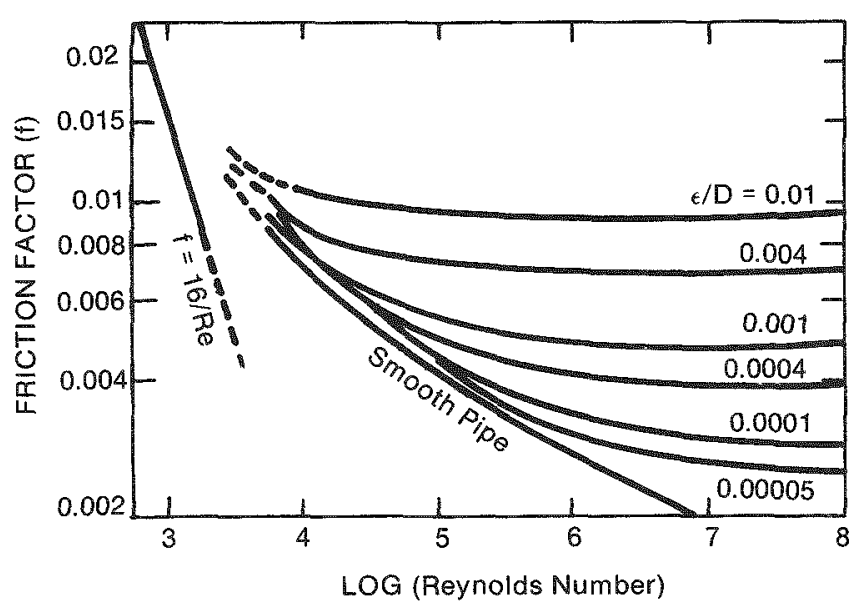

FIGURE 2. Friction Factors for Flow in Tubes

The effect of surface roughness on friction factor is shown in Figure 2. The rela tive roughness, $\epsilon / D$, of the tube enters in to the correlation, where $\epsilon$ is the height of the protuberances and D is the diameter of the tube.

The Reynolds number $(\mathrm{Re})$ is calculated by the relationship:

$$
\operatorname{Re}=\frac{D \bar{V} \rho}{\eta}
$$

Where: $\mathrm{D}=$ diameter of the gate $=1.905 \mathrm{~cm}$ $(0.75$ in.)

$\bar{V}=$ velocity of the metal $=65.8 \mathrm{~cm} / \mathrm{sec}$

$\rho=$ density of the metal $=16 \mathrm{~g} / \mathrm{cm}$

$\eta=$ viscosity of the metal $=0.05 \mathrm{~g} / \mathrm{cm}-\mathrm{sec}$

Substituting these values into Equation 2 gives a value of 40,134 for the Reynolds number.

If a coating is made from $10-\mu \mathrm{m}$ particles, this would be the maximum average height of the protrusions. In a 0.75 -inch gate, the relative roughness would be $\frac{10}{25 \times 750}=0.00053$. The

Reynolds number for metal in the gate area is 40,000; and from Figure 2, the friction factor would be about 0.0059 for a rough pipe and about 0.0055 for a smooth pipe.
Therefore: $\frac{\overline{\mathrm{V}}_{\text {Rough }}^{2}}{\overline{\mathrm{V}}_{\text {Smooth }}^{2}}=\frac{\left(\frac{1}{2 \mathrm{f}_{\mathrm{r}}}\right)\left(\frac{\mathrm{D}}{\mathrm{L}}\right)\left(\frac{\Delta \mathrm{P}}{\rho}\right)}{\left(\frac{1}{2 \mathrm{f}_{\mathrm{S}}}\right)\left(\frac{\mathrm{D}}{\mathrm{L}}\right)\left(\frac{\Delta \mathrm{P}}{\rho}\right)}$

$\frac{\bar{V}_{\text {Rough }}}{\overline{\mathrm{V}}_{\text {Smooth }}}=\sqrt{\frac{\mathrm{f}_{\mathrm{s}}}{\mathrm{f}_{\mathrm{r}}}}=\sqrt{\frac{0.0055}{0.0059}}=\sqrt{0.93}=0.965$

Thus, the metal would lose about $3.5 \%$ of its velocity because of the roughness imparted by the coating. If the diameter is reduced to $1 / 8 \mathrm{inch}$, the metal will lose about $17 \%$ of its velocity. These reductions in velocity are not considered excessive, particularly in view of the fact that they represent losses in tubes. The actual configuration of the gate and casting more approximates a plate, and the velocity loss should be less. For a rectangular gate, the smaller dimension is controlling. Thus, for a $1 / 8$-inch by $3 / 4$-inch gate, the $1 / 8$-inch dimension is the most critical, so that in this application surface roughness could result in up to $17 \%$ loss in metal velocity.

\section{Conductance as a Function of Coating Thickness}

This section considers the influence of the insulating coating thickness on the heat flux. For a steel die with no coating, Figure 3 applies and the steady state heat flux, $q$, is given by:

$$
q=\frac{k\left(T_{1}-T_{2}\right)}{L}
$$

Where: $\mathrm{k}=$ thermal conductivity of the die material $=0.062 \mathrm{cal} / \mathrm{cm}-\mathrm{sec}-{ }^{\circ} \mathrm{C}$

$$
\begin{aligned}
\mathrm{T}_{1} & =\text { plutonium temperature }=950{ }^{\circ} \mathrm{C} \\
\mathrm{T}_{2} & =\text { initial die temperature }=450{ }^{\circ} \mathrm{C} \\
\mathrm{L} & =\text { die thickness }=1 / 8 \text { inch }=0.3175 \mathrm{~cm} \\
\mathrm{q} & =\frac{0.062(950-450)}{0.3175}=97.64 \mathrm{cal} / \mathrm{sec}
\end{aligned}
$$

To calculate the steady-state heat flux for a die with an insulating coating, Figure 4 is used. In this case, the ceramic coating produces a series 
composite wall. For this situation, the heat flux is determined by:

$$
q=\frac{\left(T_{0}-T_{2}\right)}{\frac{L_{1}}{k_{1}}+\frac{\left(L_{2}-L_{1}\right)}{k_{2}}}
$$

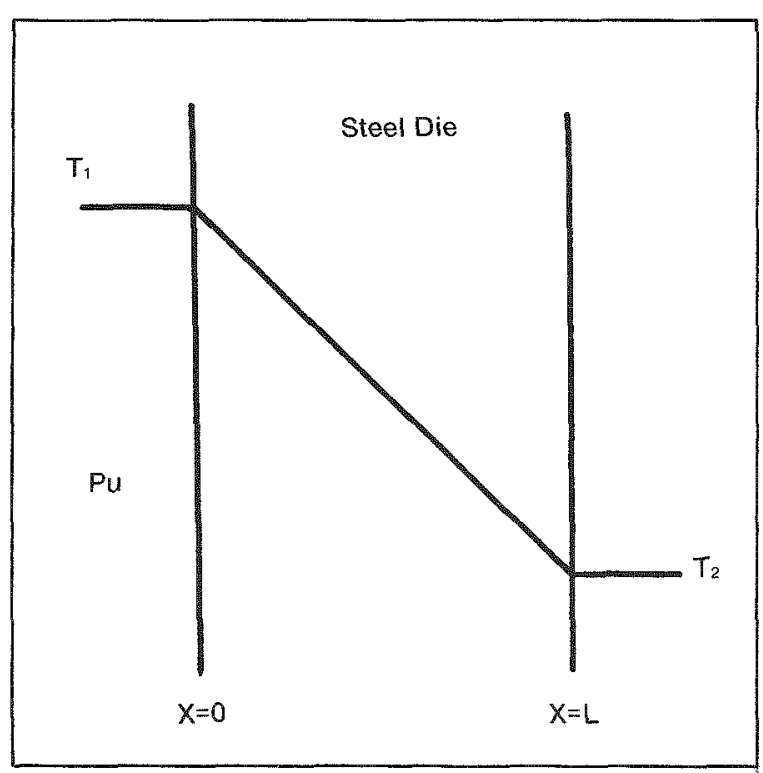

FIGURE 3. Temperature Distribution in a Die With No Coating

FIGURE 4. Temperature Distribution of a Coated Die

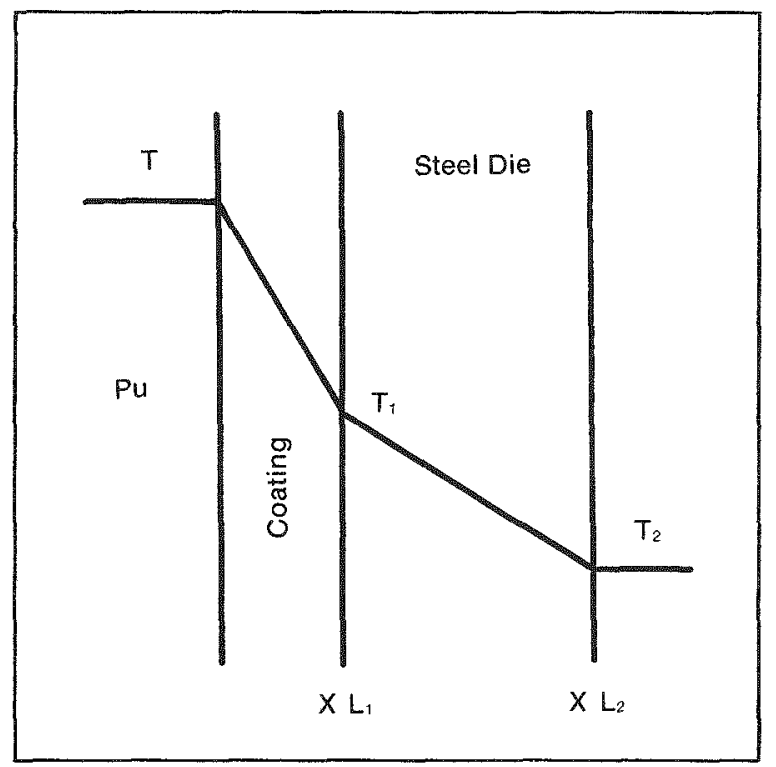

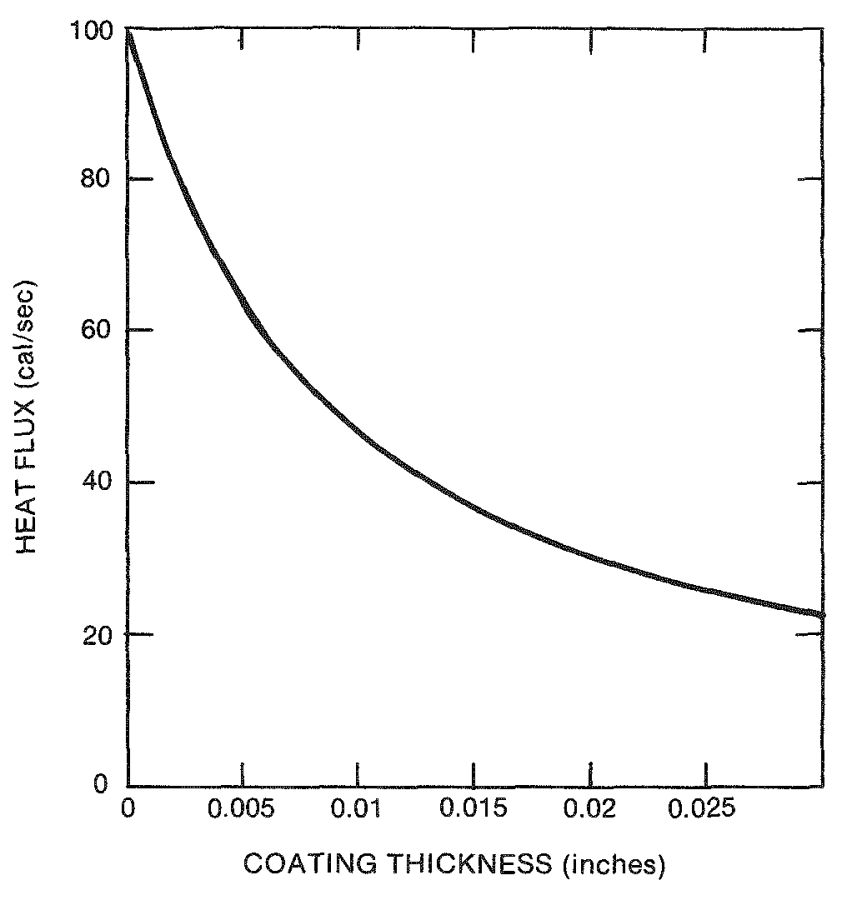

FIGURE 5. Heat Flux as a Function of Coating Thickness for a $\mathrm{ZrO}_{2}$ Coating

Where: $\mathrm{k}_{1}=$ thermal conductivity of the coating $\left(\mathrm{ZrO}_{2}\right)=0.0045 \mathrm{cal} / \mathrm{cm}-\mathrm{sec}-{ }^{\circ} \mathrm{C}$ (100\% dense)

$$
\begin{aligned}
\mathrm{k}_{2}= & \text { thermal conductivity of } \\
& \text { steel }=0.062 \mathrm{cal} / \mathrm{cm}-\mathrm{sec}^{\circ} \mathrm{C}
\end{aligned}
$$

Use of this relationship as presented assumes that the heat transfer coefficient at $\mathrm{x}=0$ and at $\mathrm{x}=\mathrm{L}_{2}$ is infinity.

Figure 5 shows the results of using Equations 3 and 4 to show the heat flux as a function of coating thickness. To fill the mold with molten metal with the same heat losses provided by the insulating coating, Equation 2 shows that the die temperature must be increased. Using Equation 2, it can be shown that to reduce the heat flux to the same value provided by a 0.020 -inch coating $(30 \mathrm{cal} / \mathrm{sec})$, the die temperature would have to be about $794^{\circ} \mathrm{C}$. With presently available materials, this would not be possible. Therefore, an insulating coating is an effective alternative to increasing the die temperature. 
Conductivity of Coatings as a Function of Porosity

High-density coatings are very difficult to apply uniformly to irregular shapes and have poor mechanical strength. Thermal expansion mismatch between the coating and the substrate usually results in spallation of the coating. Low-density coatings can be easily applied by spraying with a suspension of fine powder in water.

Therefore, it is necessary to determine the effect of porosity on the effective thermal conductivity of a coating. In this analysis, a coating is assumed to be loose packing in which the gas phase is continuous. At low porosities, the effective thermal conductivity is approximated by ${ }^{2}$

$$
\mathrm{k}_{\text {eff }}=\mathrm{k}_{\mathrm{c}}(1-\omega)
$$

Where: $\mathrm{k}_{\mathrm{c}}=$ thermal conductivity of the

$$
\omega=\text { porosity }
$$

However, at porosities above approximately 0.2 , the pores are not simple isolated shapes; porosity becomes continuous, and the conductivity of the gas phase becomes important.

When the effective pore dimensions are of the same order of magnitude as the mean free path of the gas, the true thermal conductivity of the gas decreases. Deissler and Eian ${ }^{3}$ developed a correlation for calculating the breakaway pressure, $\mathrm{P}_{\mathrm{b}}$, above which no correction for pore size on effective conductivity of the gas phase is required.

$$
P_{b}=\left(1.77 \times 10^{-21}\right) \frac{T}{D_{p} d^{2}}
$$

Where: $\mathbf{T}=$ absolute temperature, ${ }^{\circ} \mathrm{R}$

$$
\begin{aligned}
D_{p} & =\text { average particle diameter, feet } \\
d & =\text { mean diameter of gas particles, feet }
\end{aligned}
$$

Assuming $\mathrm{T}=560^{\circ} \mathrm{C}=1500^{\circ} \mathrm{R}, \mathrm{D}_{\mathrm{p}}=5$ microns $=$ $1.64 \times 10^{-5} \mathrm{ft}, \mathrm{d}=4$ angstroms $=1.31 \times 10^{-9} \mathrm{ft}$, then $P_{b}=9.43 \times 10^{4} \mathrm{lb} / \mathrm{ft}^{2}$. Since the atmospheric pressure is less than this, the thermal conductivity of the gas phase must be calculated.

When the actual pressure is less than the breakaway pressure, the thermal conductivity of the gas phase, $\mathrm{k}_{\mathrm{g}}$, should be calculated by:

$$
\mathrm{k}_{\mathrm{g}}=\frac{\mathrm{k}_{\mathrm{g}}^{\circ}}{1+2.03 \times 10^{-22}\left(\frac{\mathrm{Cp} / \mathrm{Cv}}{1+\mathrm{Cp} / \mathrm{Cv}}\right)\left(\frac{1-\omega}{\omega}\right) \frac{\mathrm{T} \mathrm{k}_{\mathrm{g}}^{\circ}}{\mathrm{P}^{\mathrm{D}_{\mathrm{p}} \mathrm{d}^{2} \mathrm{Cp} \eta}}}
$$

Where: $\mathrm{k}_{\mathrm{g}}=$ thermal conductivity of gas at standard temperature and pressure

$$
\mathrm{Cp}=\text { heat capacity of gas at constant }
$$
pressure

$$
\mathrm{Cv}=\text { heat capacity of gas at constant }
$$
volume

$$
\begin{aligned}
& P=\text { pressure } \\
& \eta=\text { viscosity of gas } \\
& \omega=\text { porosity }
\end{aligned}
$$

If argon is assumed to be the cover gas, $\mathrm{Cp}=0.1233$ $\mathrm{Btu} / \mathrm{lb} \mathrm{m}^{-}{ }^{\circ} \mathrm{F}, \mathrm{Cv}=0.0746 \mathrm{Btu} / \mathrm{lb}_{\mathrm{m}}{ }^{\circ} \mathrm{F}, \eta=0.11$ $\mathrm{lb}_{\mathrm{m}} / \mathrm{ft}-\mathrm{hr}$, and $\mathrm{k}_{\mathrm{g}}=0.02 \mathrm{Btu} / \mathrm{hr}_{\mathrm{f}}-\mathrm{ft}{ }^{\circ} \mathrm{F}$. Using these values, Equation 7 reduces to:

$$
\mathrm{k}_{\mathrm{g}}=\frac{0.02}{1+4.687 \frac{(1-\omega)}{\omega}}
$$

Using this equation, the conductivity of argon in the pores as a function of porosity is given in Figure 6.

When the conductivity of the gas is known, the ratio

$$
\frac{\mathrm{k}_{\mathrm{s}}}{\mathrm{k}_{\mathrm{g}}}=\frac{\text { conductivity of the solid }}{\text { conductivity of the gas }}
$$

can be calculated and, with the aid of Figure 7, can be used to determine the ratio

$$
\frac{\mathrm{k}_{\mathrm{b}}}{\mathrm{k}_{\mathrm{g}}}=\frac{\text { conductivity of the coating }}{\text { conductivity of the gas }}
$$




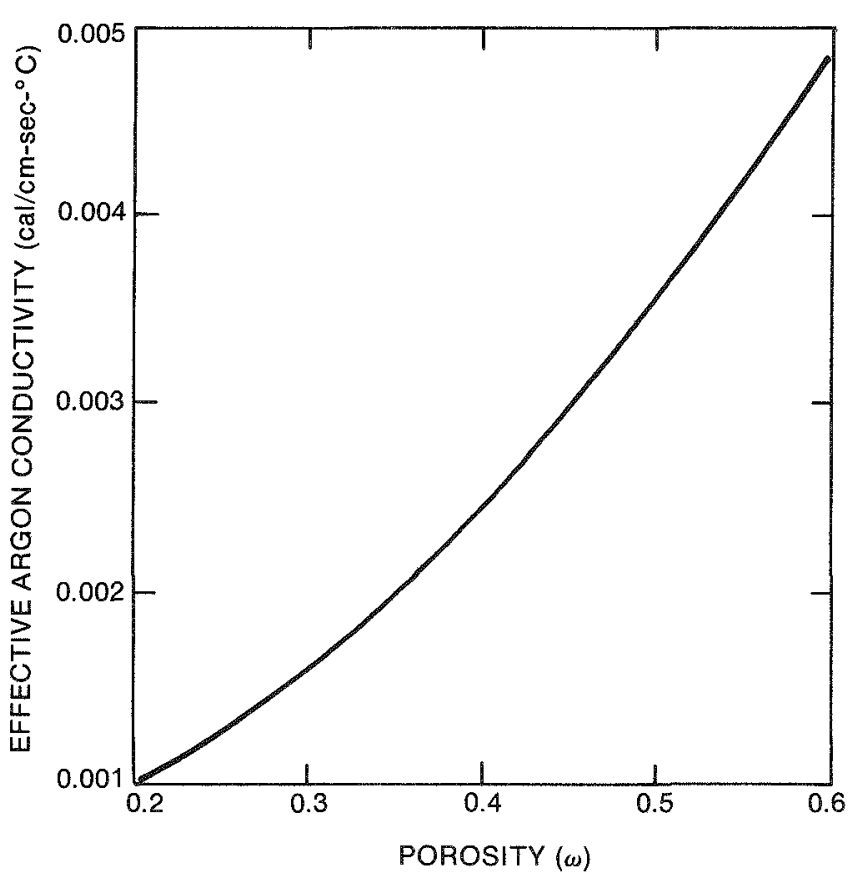

FIGURE 6. Effective Argon Conductivity as a Function of Porosity

FIGURE 7. Effect of Porosity on Packed Bed Thermal Conductivity. (From Deissler and Eian ${ }^{3}$ )

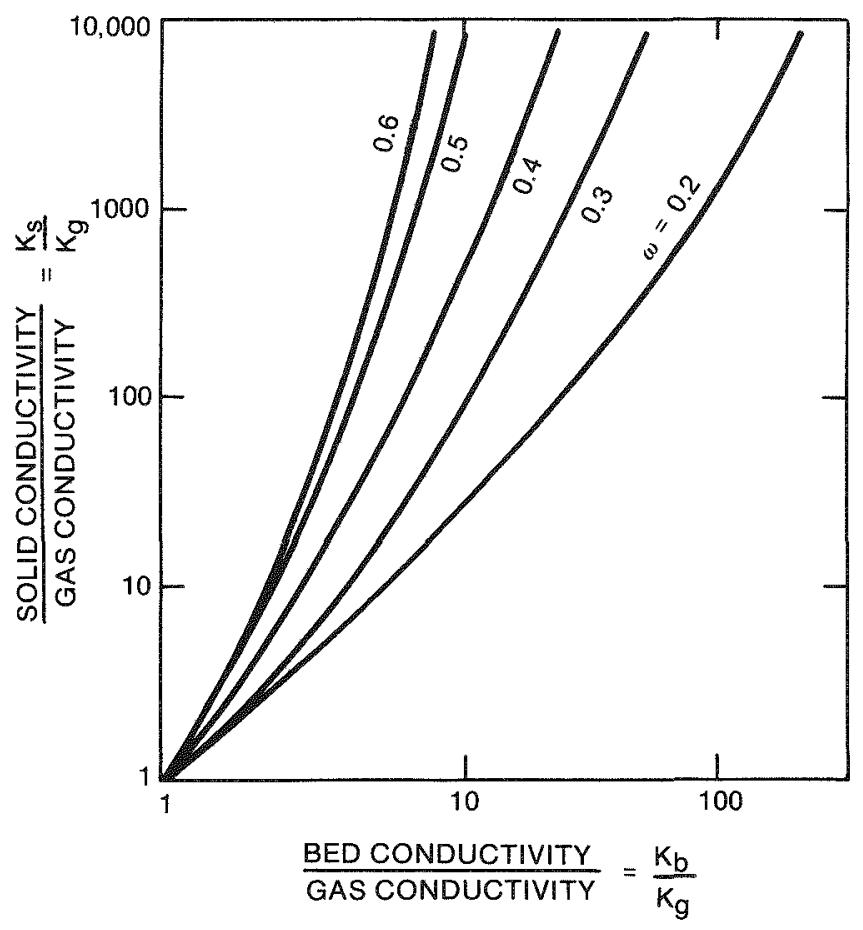

for a given porosity. From this ratio, the value of the packed bed thermal conductivity can be determined. The results of these calculations are

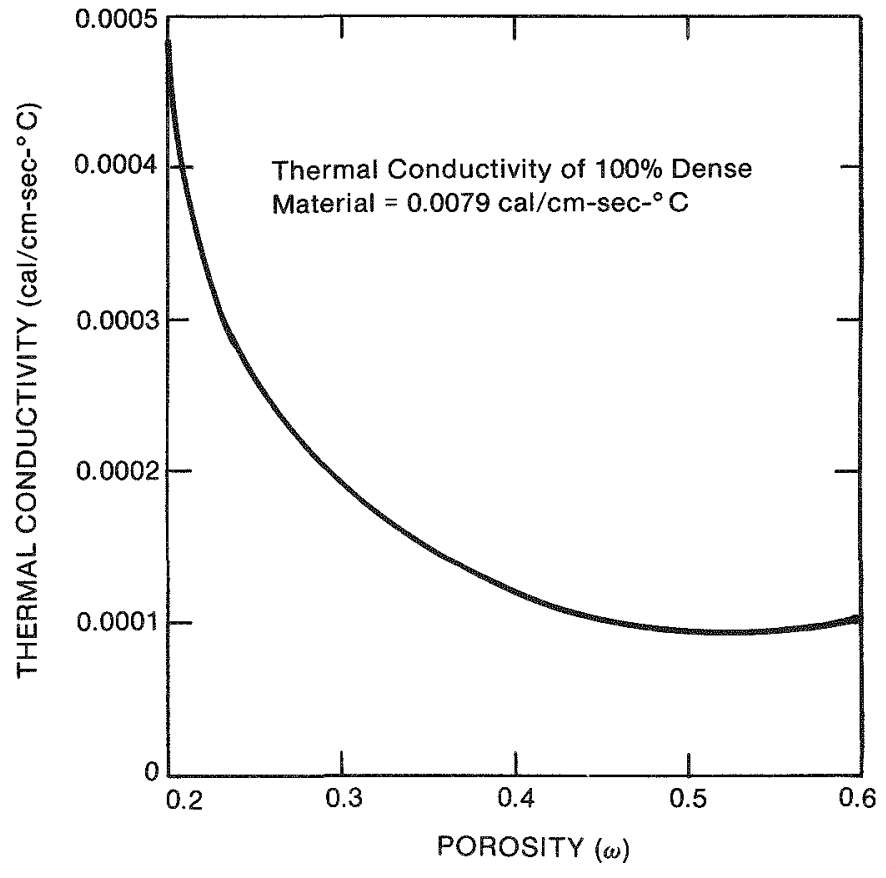

FIGURE 8. Thermal Conductivity of Porous Solid as a Function of Porosity

summarized in Figure 8 , which shows a minimum value of about 0.5 porosity. It should be noted that this minimum value is about $1 / 80$ of $100 \%$ dense $\mathrm{ZrO}_{2}$. This shows that a 0.001 -inch porous coating is a better insulator than a 0.020 -inch high-density coating.

\section{Solidification of Microspheres}

During the early stage of the pole-feed die casting effort, defects were observed in castings that appeared to be related to cold shuts but had the appearance of splattered metal. Some of the defects appeared to be small microspheres partially surrounded by metal. The usual term for this type of defect is cold shot. ${ }^{4}$ In an attempt to resolve the nature of these defects and to suggest methods of eliminating them, calculations were performed to:

1. Determine the time to solidification of various sized microspheres.

2. Determine the die temperature required to delay solidification time of a microsphere until it can be surrounded by incoming metal. 
3. Determine the time required to remelt a microsphere once it is formed.

4. Repeat the above calculations by assuming an insulating coating.

The calculations presented here are first-order calculations only and do not consider all possible influences. The assumptions involved are delineated where applicable.

These calculations are based on the assumption that a microsphere of radius, $r$, will form during injection of metal into the mold and come to rest along the mold wall where cooling and solidification take place. The microsphere is assumed to be in contact with the mold wall over a radius of $2 / 3 \mathrm{r}$. In view of the size of the microspheres, temperature gradients within the sphere are considered negligible. In addition, it is assumed that the densities of liquid and solid plutonium are equal. This is a reasonable assumption. Under these conditions, the time (in seconds) for solidification can be determined by Chvorinov's rule. ${ }^{2}$

$$
\mathrm{t}=\frac{\pi}{4} \frac{1}{\mathrm{k} \rho \mathrm{Cp}}\left(\frac{\rho^{\prime} \mathrm{H}_{\mathrm{f}}^{\prime}}{\mathrm{Tm}-\mathrm{To}_{\mathrm{o}}}\right)^{2}\left(\frac{\mathrm{V}}{\mathrm{A}}\right)^{2}
$$

Where: $\mathrm{k}=$ thermal conductivity of the die $0.057 \mathrm{cal} / \mathrm{cm}-\mathrm{sec}^{\circ} \mathrm{C}$

$$
\rho=\text { density of the steel die }=7.8 \mathrm{~g} / \mathrm{cm}^{3}
$$

$\mathrm{Cp}=$ heat capacity of the steel $=0.12$ $\mathrm{cal} / \mathrm{g}-{ }^{\circ} \mathrm{C}$

$$
\rho^{\prime}=\text { density of plutonium }=16.0 \mathrm{~g} / \mathrm{cm}^{3}
$$

$\mathrm{Tm}=$ melt temperature of plutonium alloy $=670^{\circ} \mathrm{C}$

To = die temperature (variable)

$\mathrm{H}_{\mathrm{f}}=$ effective heat of fusion $=$ $\mathrm{H}_{\mathrm{f}}+\mathrm{Cp}(\Delta \mathrm{Ts})$

$\mathrm{Cp}=$ heat capacity of plutonium $=0.0435$ $\mathrm{cal} / \mathrm{g}_{-}{ }^{\circ} \mathrm{C}$
$\Delta \mathrm{Ts}=\underset{250^{\circ}}{\text { amount } \text { of superheat of the metal }=}$

$$
\begin{aligned}
& V=\text { volume of microsphere }=\frac{4 \pi r^{3}}{3} \\
& r=\text { radius of microspheres }(\mathrm{cm}) \text { (variable) }
\end{aligned}
$$

Cold shot occurrence was confined to the region of the part from the pole to about 60 degrees from the pole. This amounts to about $31 \%$ of the total volume of the casting. Therefore, for a 1 -second fill time, microspheres must take longer than 0.31 second to solidify in order to prevent microsphere formation. Figure 9 shows the results of calculations using Equation 9 and shows the time to solidification of microspheres as a function of radius at various die temperatures. This figure shows that any microsphere with a radius greater than $0.080 \mathrm{~cm}$ will take longer than 0.31 second when the die is at $300^{\circ} \mathrm{C}$. When the die is at $150^{\circ} \mathrm{C}$, the microsphere radius must be greater than $0.115 \mathrm{~cm}$.

The data of Figure 9 suggest another important consideration. For a given solidification time, the die temperature must increase as the microsphere radius decreases. This suggests that if the system is

FIGURE 9. Time for Microsphere Solidification as a Function of Sphere Radius

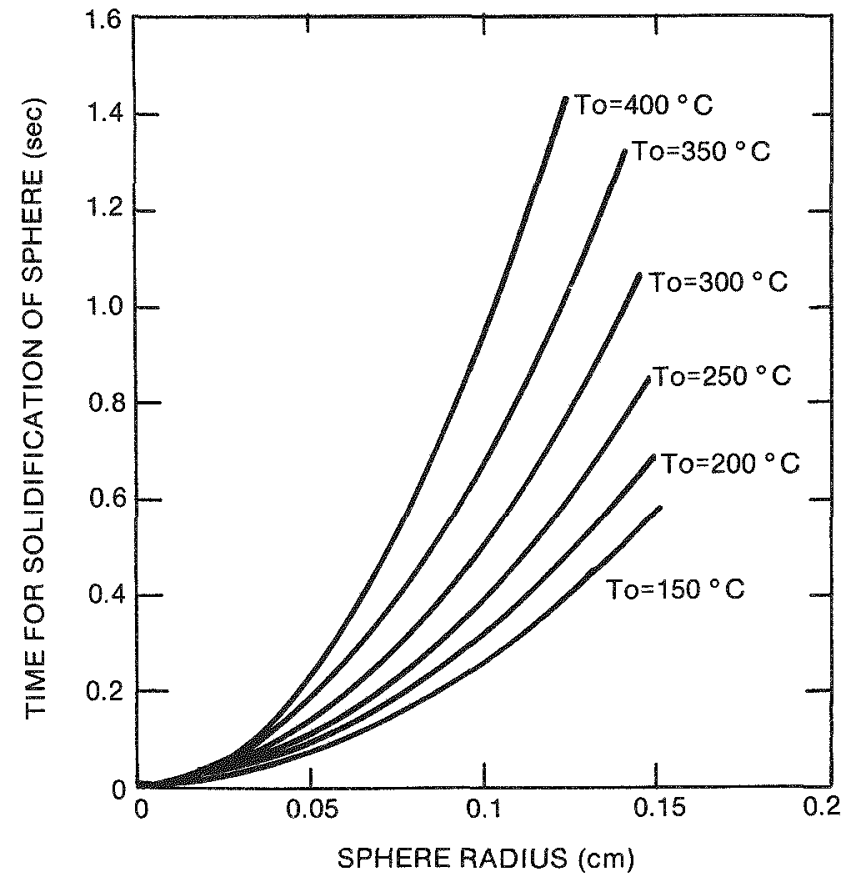


limited by the fill time (i.e., metal velocity) and if the die temperature needs to remain low, then the only option remaining is to prevent the formation of smaller microspheres. Two methods of doing this are to (1) reduce the turbulence of the metal stream by redesigning the gate area or (2) use a two-stage pressurization process so that small microspheres will not form. In Stage 1, the metal is introduced at a low velocity so that no splattering occurs. When a predetermined amount of metal is injected, the second, high-velocity stage is initiated. The metal in the mold provides a dampening effect on the high-velocity metal and minimizes splattering.

\section{Effect of Insulating Coatings}

If an insulating coating such as $\mathrm{ZrO}_{2}$ or $\mathrm{Er}_{2} \mathrm{O}_{3}$ is applied to the die, the time to solidification of a microsphere can be calculated from

$$
\begin{array}{ll}
\mathrm{k}=\text { thermal conductivity of } \begin{aligned}
\mathrm{ZrO}_{2}= & \begin{array}{l}
0.0049 \\
\mathrm{cal} / \mathrm{sec}-\mathrm{cm}^{-}{ }^{\circ} \mathrm{C}
\end{array} \\
\rho=\text { density of } \mathrm{ZrO}_{2} & =5.50 \mathrm{~g} / \mathrm{cm}^{3}
\end{aligned} \\
\mathrm{C}_{\mathrm{p}}=\text { heat capacity of } \mathrm{ZrO}_{2} & =0.103 \mathrm{cal} / \mathrm{g}{ }^{\circ} \mathrm{C}
\end{array}
$$

FIGURE 10. Effect of Die Temperature on Solidification Time of Microspheres of Varying Radii

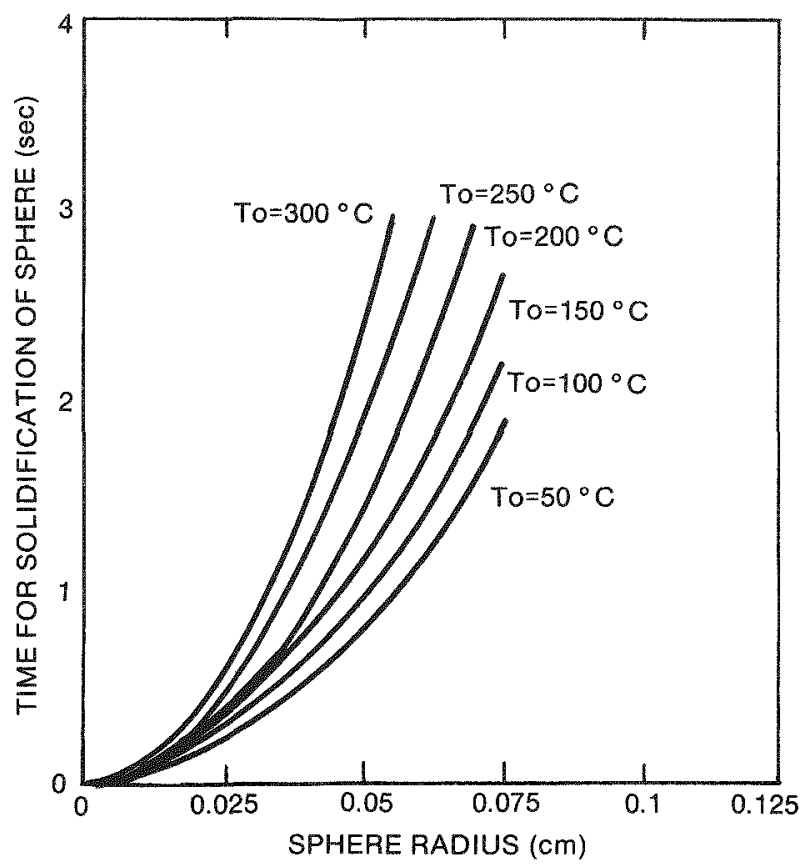

The assumption here is that for the fill time under consideration, the coating is thick enough that effect of the steel die on the molten metal is negligible.

The results of these calculations are summarized in Figure 10. Because of the differences in thermal conductivity, density, and heat capacity of the coating compared with the steel, the time to solidification is about 20 times longer with the insulating coating than with the steel die. These calculations were based on a $100 \%$ dense coating. For low-density coatings, the time to solidification would be even longer than shown in Figure 10. The figure also shows that with a coating temperature of $300^{\circ} \mathrm{C}$, only microspheres with a radius less than $0.019 \mathrm{~cm}$ will solidify in less than 0.31 second.

\section{Remelting of Microspheres}

Once microspheres are formed, it is expected that most are remelted by late-arriving molten metal. Understanding conditions under which remelting does not occur may be helpful to explain some defects observed in die casting.

The most rapid remelting occurs when the microsphere is completely surrounded by molten metal. However, this condition does not usually occur because a portion of the microsphere touches the mold wall. Molten metal cannot completely surround the microsphere because of this contact surface. In addition to this, heat is continually being extracted by the mold wall over this area. Figure 11 shows that:

$$
\begin{gathered}
\Delta \mathrm{Q}=\mathrm{Q}_{\text {in }}-\mathrm{Q}_{\text {out }} \\
\Delta \mathrm{Q}=\frac{2 \mathrm{~A}^{\prime} \mathrm{D}^{\prime}(\mathrm{T} \ell-\mathrm{Ts}) \sqrt{\mathrm{t}}}{\sqrt{\pi \mathrm{k}^{\prime} \rho^{\prime} \mathrm{Cp}}}-\frac{2 \mathrm{Ak}(\mathrm{Tm}-\mathrm{To}) \sqrt{\mathrm{t}}}{\sqrt{\pi \mathrm{k} \rho \mathrm{Cp}}}
\end{gathered}
$$

Where: $\Delta \mathrm{Q}=$ Quantity of heat retained by microsphere

$$
\begin{aligned}
& \mathrm{A}^{\prime}=\text { area of sphere in contact with molten } \\
& \text { metal }
\end{aligned}
$$




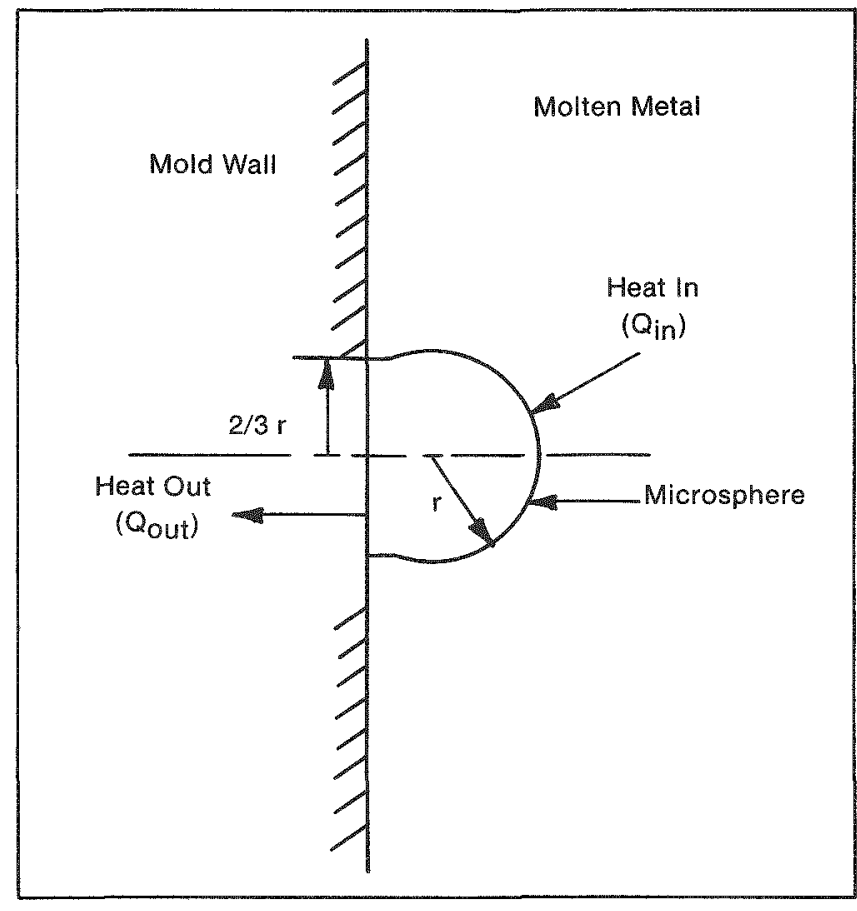

FIGURE 11. Microsphere at the Die-Cavity Interface

$$
\begin{aligned}
& A=\text { area of sphere in contact with the } \\
& \mathrm{T} \ell=\text { temperature of liquid metal } \\
& \mathrm{Ts}=\text { temperature of solid metal in the }
\end{aligned}
$$

The primed symbols refer to plutonium values and the unprimed symbols refer to steel values.

After the appropriate substitutions,

$$
\Delta Q=21042 r^{2} \sqrt{t}
$$

When $\triangle Q$ equals the modified heat of fusion, $H_{f}^{\prime \prime}$, the microsphere will be molten.

$$
\mathrm{H}_{\mathfrak{f}}^{\prime \prime}=\left(\mathrm{H}_{\mathrm{f}}+\mathrm{Cp} \Delta \mathrm{T}\right)
$$

Where: $\quad \Delta \mathrm{T}=\mathrm{Tm}-\mathrm{Ts}$
Therefore, $H_{f}^{\prime \prime}=(3.13+0.0435 \Delta T)$

$$
\begin{aligned}
& =21042 \mathrm{r}^{2} \sqrt{t} \\
t & =\frac{(3.13+0.0435 \Delta \mathrm{T})^{2}}{\left(21042 \mathrm{r}^{2}\right)^{2}}
\end{aligned}
$$

This relationship can be used to estimate the time to remelt a given sized microsphere at a given temperature. The results of calculations based on this relationship are summarized in Figure 12 and suggest that the time to remelt is rather short, even for large spheres. However, these calculations assume the spheres are immediately surrounded by molten metal and do not consider time for them to cool below the melting point. The time required to cool to Ts must be added to the remelt time.

This time can be approximated by using the time to solidify a microsphere over T - Tm to obtain a cooling rate and assuming the same cooling rate below Tm. Then, the values can be added to those used to produce Figure 12; the result is shown in Figure 13. In view of the many assumptions involved, it is not expected that the absolute values

FIGURE 12. Time Required to Remelt Microspheres at Various Sphere Sizes and Super Cooling Required

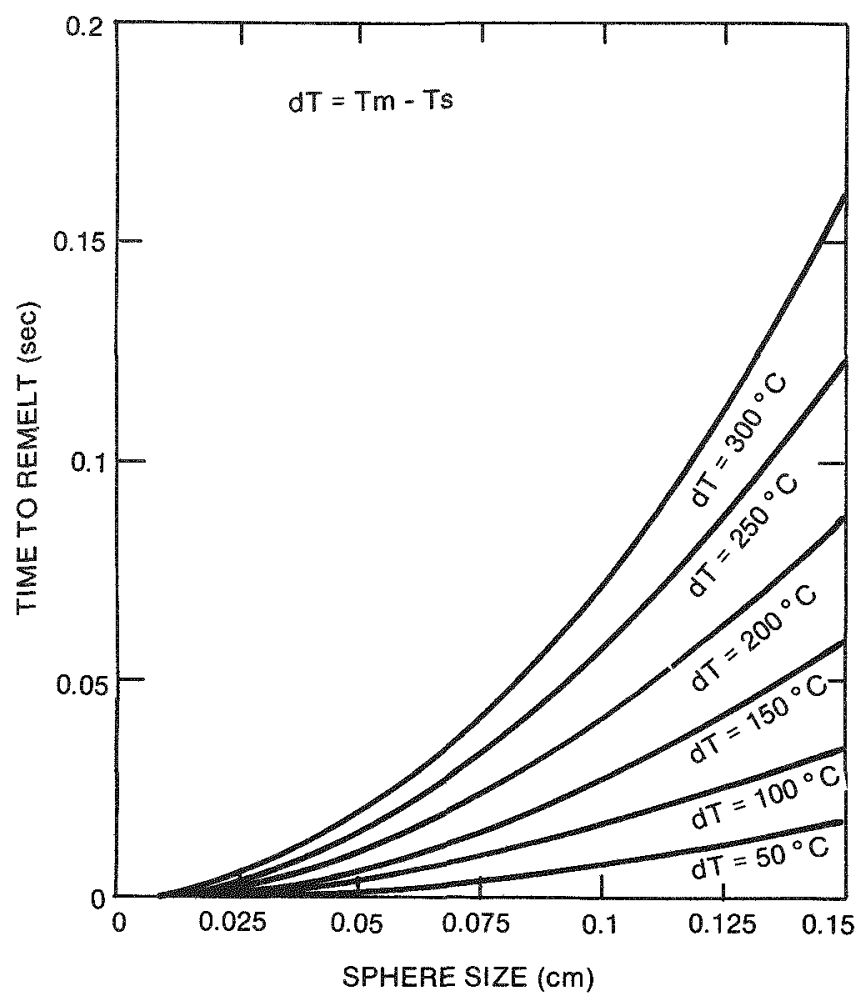




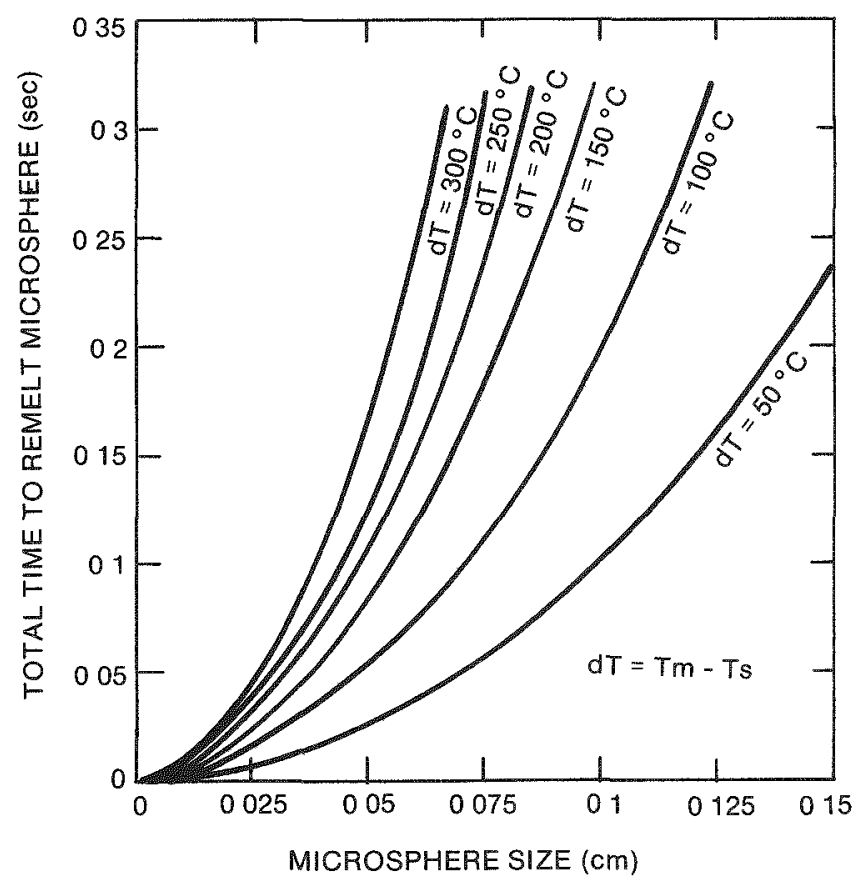

FIGURE 13. Total Time Required to Cool and Remelt Microspheres

calculated are accurate, but the trends indicated are certainly reasonable. Figure 13 suggests it is reasonable to assume that once formed, some microspheres will not remelt in the 0.31 second required to fill the mold cavity to $31 \%$ of the metal volume.

\section{Experimental Work}

\section{Comparative Insulating Value of Coatings}

Experimental work was conducted in conjunction with the calculations performed on various aspects of coatings. In essence, this work was to study the effect of various coatings on the heat removal rate during solidification of lead. Crucibles of $\mathrm{H}-13$ tool steel were used with the experimental arrangement shown in Figure 14. For comparison, uncoated graphite crucibles were also used as shown in Figure 15. Two types of measurements were made during these tests:

1. Wall temperature

2. Thermal arrest

Initial tests were conducted by welding thermocouples to the inside of the crucible at the bottom

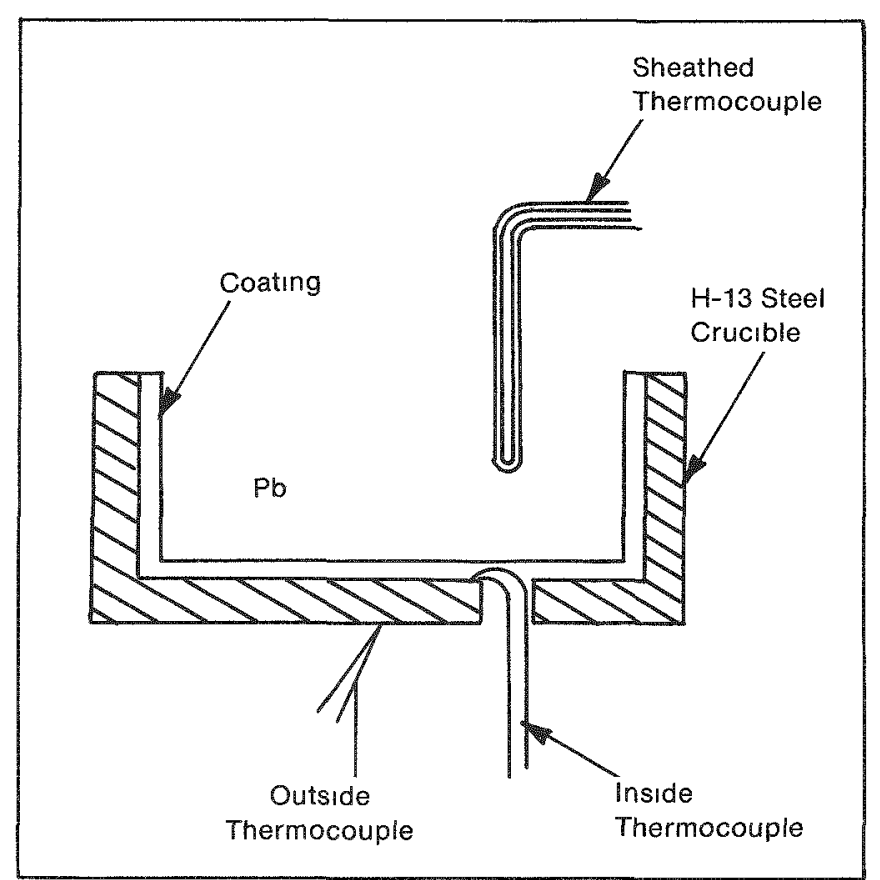

FIGURE 14. H-13 Tool Steel Crucibles Used in Experimental Work. The sheathed thermocouple was used only for the thermal arrest measurements.

FIGURE 15. Graphite Crucible Used in Experimental Work

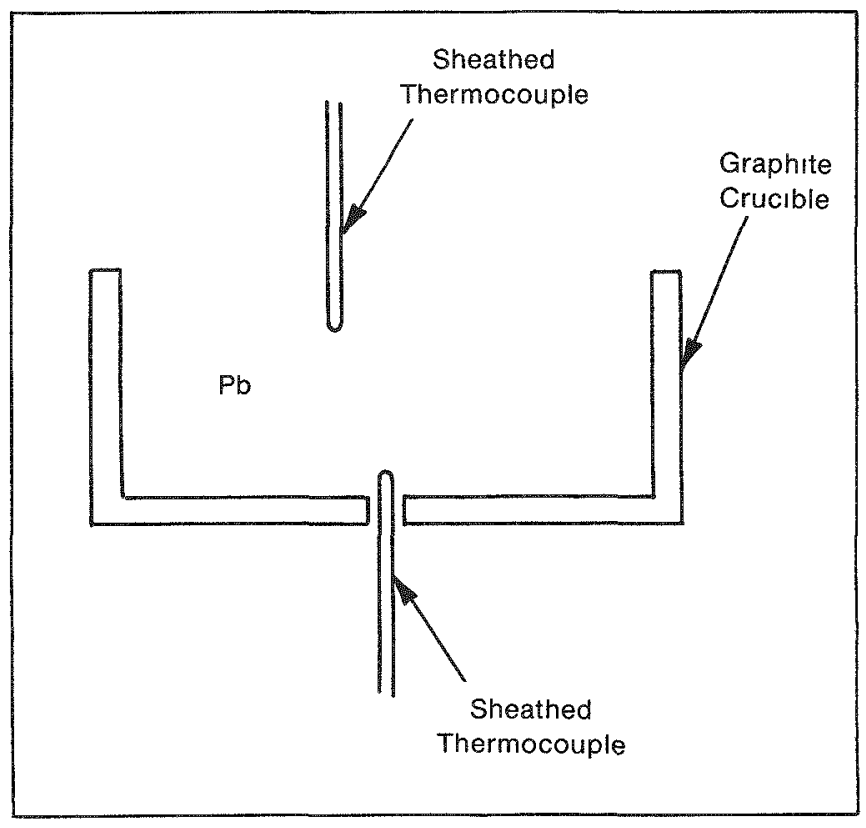

as well as to the outside of the crucible opposite the inner thermocouple, as shown in Figure 14. 
Coatings were applied over the inner thermocouple, which was located between the coating and the steel crucible. Molten lead at $600{ }^{\circ} \mathrm{C}$ was recorded as a function of time. From these data, the maximum temperature at each location was determined, as well as the time required to achieve this maximum temperature.

Temperature profiles similar to those shown in Figures 16-19 were obtained. In these figures, the temperature measured by the inside thermocouple between the coating and the steel can qualitatively measure the relative insulating value of the coating. The higher the wall temperature at a given time, the lower the insulating value of the coating. Thus, in Figure 16, the phosphate coating is the poorest insulator, and $\mathrm{CaO}$ is the best.

The advantage of this method is its precise thermocouple location. However, its results cannot be quantified. Changes in the amount of metal or melt temperature can affect the total system heat content and temperature. For this reason, the method was abandoned in favor of the thermal arrest method.

FIGURE 16. Temperature Versus Time Profiles Obtained by the Wall Temperature Measurement Method for $\mathrm{ZrO}_{2}$ and $\mathrm{CaO}$

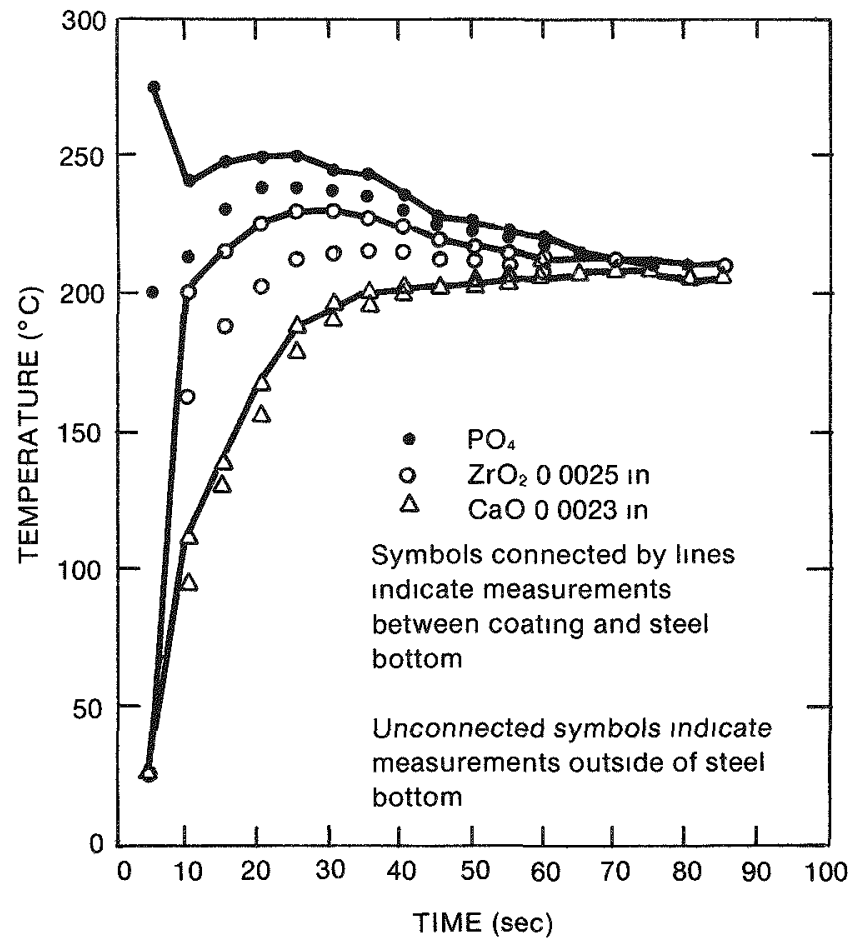

Several coatings were tested by this method and curves shown in Figures 16 and 17 were obtained. These curves yielded the following information:

1. $\mathrm{CaO}, \mathrm{Er}_{2} \mathrm{O}_{3}$, and $\mathrm{ZrO}_{2}$ have similar insulating capabilities.

2. Thick coatings provide more insulating capability than thin coatings.

3. $\mathrm{Er}_{2} \mathrm{O}_{3}$ and $\mathrm{Y}_{2} \mathrm{O}_{3}$ have similar insulating capabilities with $\mathrm{Y}_{2} \mathrm{O}_{3}$ being slightly better.

The H-13 tool steel crucibles used in the wall temperature measurements were also used for thermal arrest tests with the addition of a sheathed thermocouple in the center of the lead (Figure 14). The graphite crucible shown in Figure 15 was also used for comparison. The temperature of the sheathed thermocouple was recorded to produce a cooling profile of the lead. The pouring temperature of the lead in each case was $600^{\circ} \mathrm{C}$. The insulating value of any coating was determined by duration of the thermal arrest as shown in Figure 20. The

FIGURE 17. Temperature Versus Tme Profiles Obtained by the Wall Temperature Measurement Method for $\mathrm{Er}_{2} \mathrm{O}_{3}$ and $\mathrm{ZrO}_{2}$

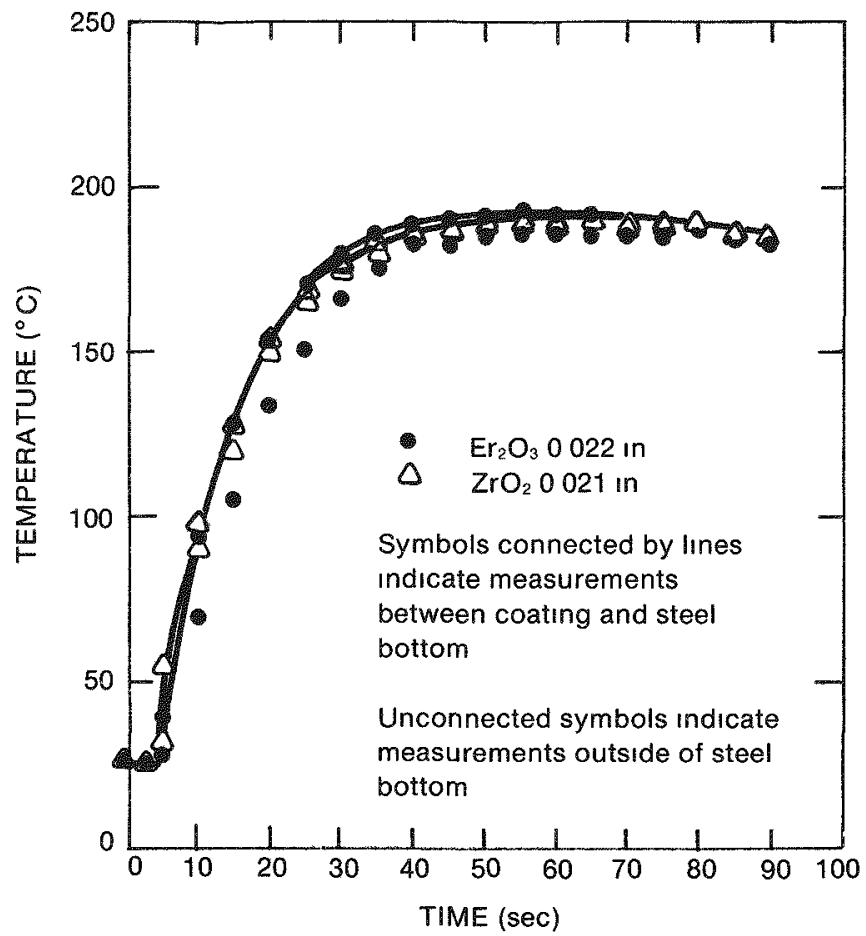




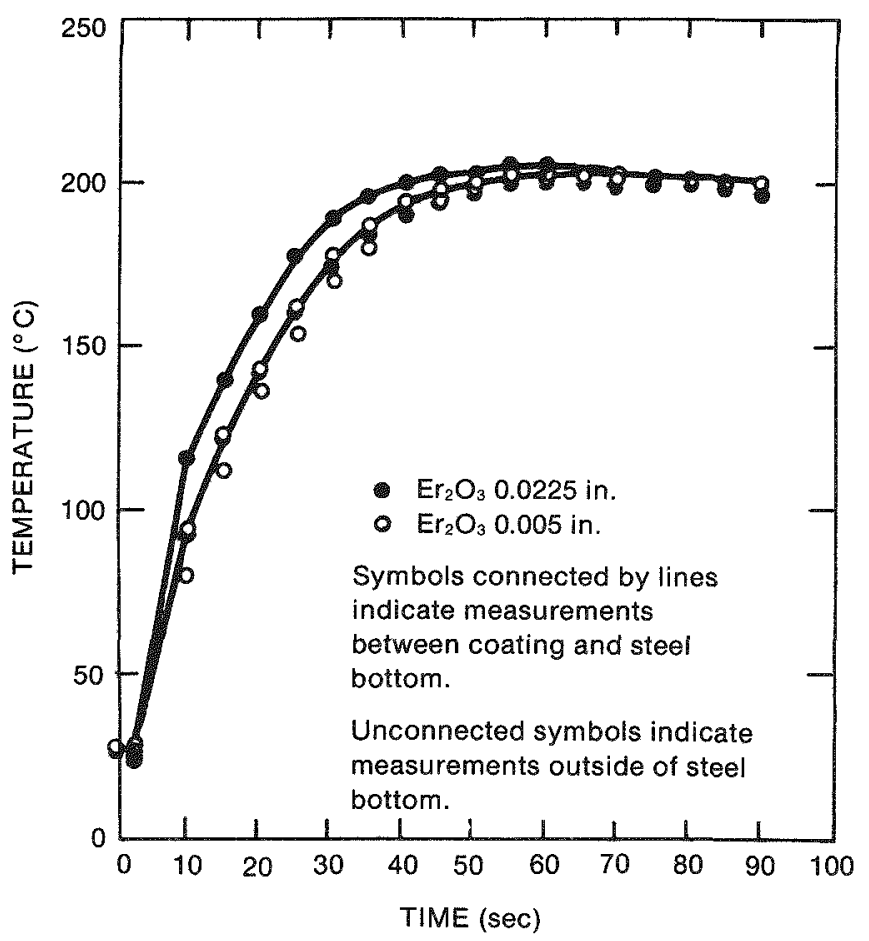

FIGURE 18. Temperature Versus Time Profiles Obtained by the Wall Temperature Measurement Method for two Thicknesses of $\mathrm{Er}_{2} \mathrm{O}_{3}$ Coating

FIGURE 19. Temperature Versus Time Profiles Obtained by the Wall Temperature Measurement Method for $\mathrm{Er}_{2} \mathrm{O}_{3}$ and $\mathrm{Y}_{2} \mathrm{O}_{3}$

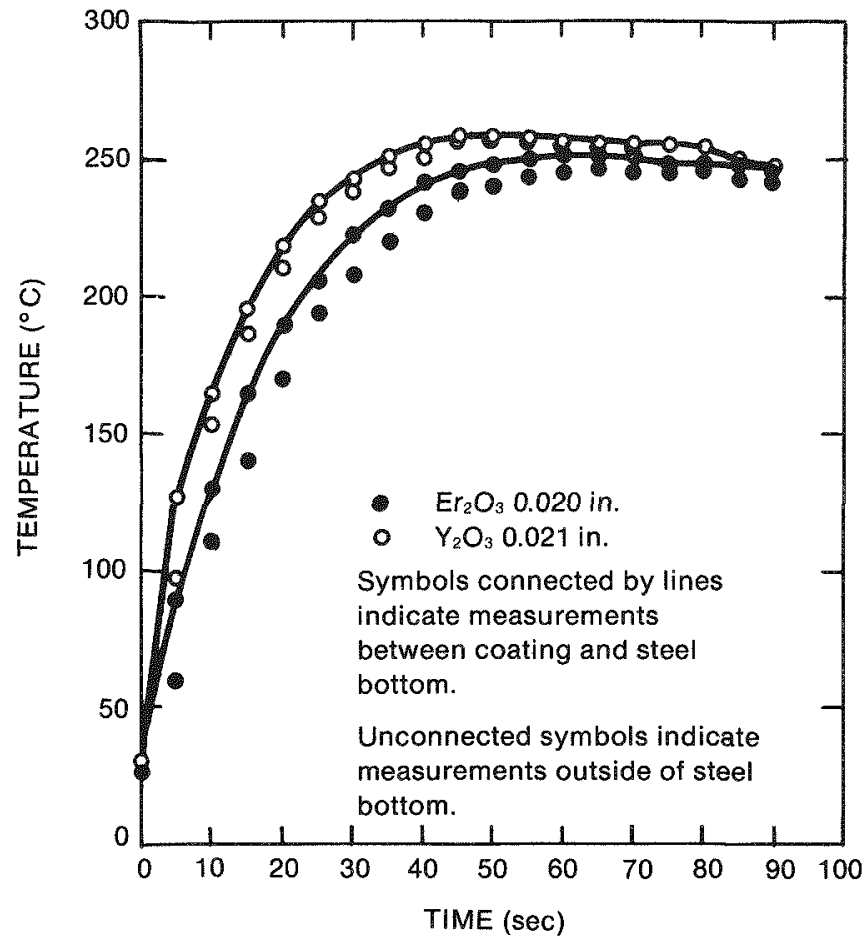

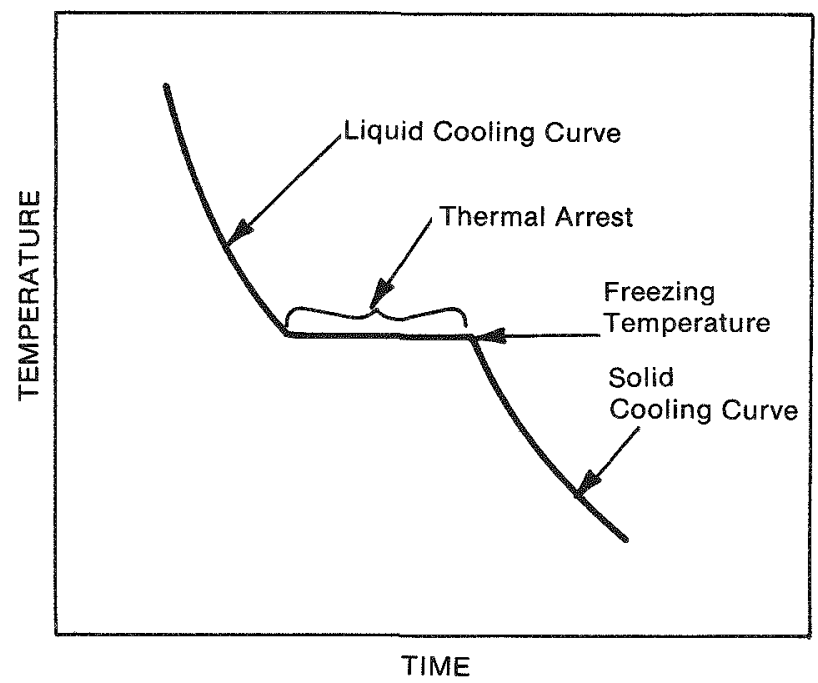

FIGURE 20. Thermal Arrest Obtained on Solidification of a Pure Metal

FIGURE 21. Length of Thermal Arrest as a Function of Crucible Temperature

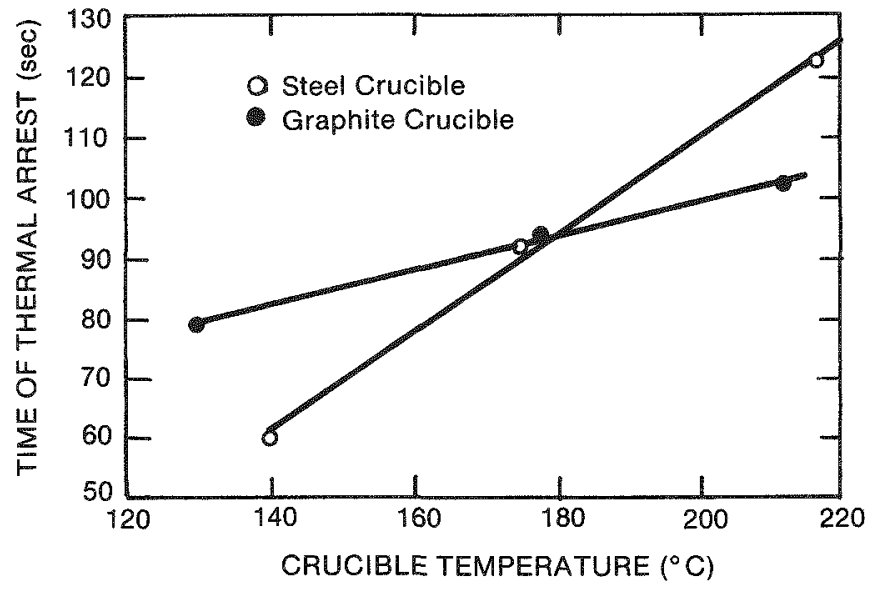

thermal arrest is produced by release of the latent heat of fusion $(6.26 \mathrm{cal} / \mathrm{g}$ for lead). The length of the thermal arrest was normalized to $90 \mathrm{~g}$ of lead to eliminate differences from different sample weights.

Various test results of steel and graphite crucibles are summarized in Table 1, and a plot of the thermal arrest length as a function of crucible temperature is given in Figure 21. The length of the thermal arrest is linear with crucible temperature for both the graphite and steel crucibles. Also, the length of the thermal arrest increases with increased coating thickness, as expected. 
TABLE 1. Tests of Steel and Graphite Crucibles Using the Thermal Arrest Method

\begin{tabular}{|c|c|c|c|}
\hline Test & System & $\begin{array}{c}\text { Temperature } \\
\left({ }^{\circ} \mathrm{C}\right)\end{array}$ & $\begin{array}{c}\text { Normalized Length } \\
\text { of Thermal Arrest } \\
\text { (sec) }\end{array}$ \\
\hline 1 & $\begin{array}{l}0.021 \text {-inch } \mathrm{Er}_{2} \mathrm{O}_{3} \\
\text { on steel }\end{array}$ & & 24.7 \\
\hline 2 & $\begin{array}{l}0.001 \text {-inch } \mathrm{Er}_{2} \mathrm{O}_{3} \\
\text { on steel }\end{array}$ & & 10.2 \\
\hline 3 & Steel, uncoated & & 4.4 \\
\hline \multirow[t]{2}{*}{4} & $\begin{array}{l}0.001 \text {-inch } \mathrm{Er}_{2} \mathrm{O}_{3} \\
\text { on steel }\end{array}$ & 140 & 60.6 \\
\hline & Graphite, uncoated & 130 & 79.3 \\
\hline \multirow[t]{2}{*}{5} & $\begin{array}{l}0.001 \text {-inch } \mathrm{Er}_{2} \mathrm{O}_{3} \\
\text { on steel }\end{array}$ & 175 & 92.1 \\
\hline & Graphite, uncoated & 178 & 94.8 \\
\hline \multirow[t]{2}{*}{6} & $\begin{array}{l}0.001 \text {-inch } \mathrm{Er}_{2} \mathrm{O}_{3} \\
\text { on steel }\end{array}$ & 216 & 122.6 \\
\hline & Graphite, uncoated & 212 & 101.6 \\
\hline
\end{tabular}

TABLE 2. Coatings Using the Thermal Arrest Method

\begin{tabular}{|c|c|c|c|}
\hline Coating & $\begin{array}{l}\text { Thickness } \\
\text { (in.) }\end{array}$ & $\begin{array}{c}\text { Number } \\
\text { Tested }\end{array}$ & $\begin{array}{c}\text { Average } \\
\text { Normalized } \\
\text { Length } \\
\text { (in.) } \\
\end{array}$ \\
\hline $\mathrm{Er}_{2} \mathrm{O}_{3}$ & 0.004 & 1 & 9.3 \\
\hline $\mathrm{Er}_{2} \mathrm{O}_{3}+\mathrm{ZrO}_{2}$ wash & 0.0002 & 1 & 4.4 \\
\hline $\mathrm{SiO}_{2}+\mathrm{Er}_{2} \mathrm{O}_{3}$ & 0.007 & 2 & 11.8 \\
\hline $\mathrm{SiO}_{2}+\mathrm{Er}_{2} \mathrm{O}_{3}$ & 0.004 & 2 & 8.9 \\
\hline $\mathrm{CaF}_{2}+\mathrm{SiO}_{2}+\operatorname{Er}_{2} \mathrm{O}_{3}$ & 0.009 & 2 & 10.2 \\
\hline $\mathrm{CaF}_{2}+\mathrm{SiO}_{2}+\mathrm{Er}_{2} \mathrm{O}_{3}$ & 0.008 & 2 & 9.5 \\
\hline $\mathrm{Er}_{2} \mathrm{O}_{3} 15 \%$ porosity & 0.0002 & 2 & 5.4 \\
\hline $\mathrm{Er}_{2} \mathrm{O}_{3} 25 \%$ porosity & 0.0002 & 2 & 5.8 \\
\hline $\mathrm{Er}_{2} \mathrm{O}_{3} 60 \%$ porosity & 0.004 & 2 & 8.7 \\
\hline
\end{tabular}

Several different coatings were produced by the Product Integrity and Surveillance group. Test results of the thermal arrest method are given in Table 2. The $\operatorname{Er}_{2} \mathrm{O}_{3}$ tests reported in Table 2 have somewhat shorter thermal arrests than similar tests summarized in Table 1. No explanation can be given for these differences although there may have been melt temperature variations at the time of pouring.
The $\mathrm{Er}_{2} \mathrm{O}_{3}$ and $\mathrm{SiO}_{2}+\mathrm{Er}_{2} \mathrm{O}_{3}$ coatings show a linear relationship between coating thickness and length of the thermal arrest, suggesting similar conductivities. However, the length of thermal arrest for the $\mathrm{CaF}_{2}+\mathrm{SiO}_{2}+\mathrm{Er}_{2} \mathrm{O}_{3}$ coating was about $25 \%$ lower than the $\mathrm{Er}_{2} \mathrm{O}_{3}$ coating, suggesting a higher thermal conductivity. A thin $\mathrm{ZrO}_{2}$ wash on top of the $\mathrm{Er}_{2} \mathrm{O}_{3}$ coating provided no increased insulation. A very thin coating provides no release capabilities- thus, no benefit.

In addition to verifying the general conclusions obtained from the wall temperature measurements, the thermal arrest method also showed (Table 1):

1. The length of the thermal arrest varies linearly with crucible temperature (Figure 21 ).

2. Low-density coatings provide better insulating capabilities than high-density coatings.

3. The length of the thermal arrest is proportional to the weight of metal.

\section{Plasma-Sprayed Coatings}

In an attempt to identify alternative coatings for the die casting program, flame-sprayed coatings were investigated for the reasons listed below:

1. A variety of materials are available commercially.

2. The process is adaptable to other materials, such as $\operatorname{Er}_{2} \mathrm{O}_{3}$ and $\mathrm{Y}_{2} \mathrm{O}_{3}$, if it shows enough promise.

3. Conceivably, thick coatings for insulating purposes can be applied uniformly by this method.

A total of six different coatings were applied to Type 430 stainless steel rods $7 / 8$ inch diameter and $43 / 4$ inches long. The rod shape was selected because of its ready adaptation to the commercial spraying procedure. The coatings were applied using powder obtained from Metco Products, Inc. and were selected on the basis of their potential compatibility with plutonium and availability as commercial coatings. At this stage of the program, 
it was not considered desirable to develop spraying parameters for noncommercial coatings. The materials selected were: $\mathrm{ZrO}_{2}, \mathrm{CaO} \mathrm{ZrO}_{2}$, $\mathrm{MgO} \mathrm{ZrO}_{2}, \mathrm{MgO} \mathrm{ZrO}_{2}+\mathrm{Ni} / \mathrm{Cr}$ alloy transition layer, $\mathrm{Cr}_{2} \mathrm{C}_{3}$, and tantalum.

Initial testing was done to evaluate the coating adherence with the stainless steel rod and to determine the compatibility of the coating with plutonium. The first experiment, designed to test the adherence of the coating with the stainless steel, consisted of thermalcycling the rods 10 times between room temperature and $600^{\circ} \mathrm{C}$. The heating rate was about $15^{\circ} \mathrm{C} / \mathrm{min}$ and the cooling rate was $2-5^{\circ} \mathrm{C} / \mathrm{min}$. All the coatings survived this test.

Following this, the rods were immersed in plutonium metal at $750^{\circ} \mathrm{C}$ for five minutes and withdrawn for five minutes. This cycle was repeated 10 times. After the first cycle, a layer of plutonium metal and plutonium oxide material began building up on the rod. This occurred on all test coatings except tantalum. Cross sections of each of the specimens are shown in Figures 22-27. Reaction layers can be seen in each of the ceramic coatings. The presence of reaction product at the interface at these short time periods indicates a propensity for reaction. At the very least, it indicates a strong tendency for wetting, which is a prerequisite for reaction. Upon wetting, a bond is produced at the ceramic-plutonium interface that could be difficult to break during part removal. For a die casting operation, this would mean difficulty in removing the part from the die without a release coating. In the tantalum only, a gray layer appears on the surface of the metal, presumably $\mathrm{Ta}_{2} \mathrm{O}_{5}$. This layer probably occurs because the material is molten during the spray process in an impure atmosphere.

An $\mathrm{H}-13$ tool steel crucible was flame spray-coated with a 0.015 -inch-thick tantalum coating and subjected to the lead solidification test. Data were accumulated for analysis by both the wall temperature method and the thermal arrest method. The results are summarized in Figure 28. Also included in this figure are analogous curves for an uncoated crucible and a crucible with a 0.001 -inch low-density $\mathrm{Er}_{2} \mathrm{O}_{3}$ coating. Some insulating capability is presented by the porous tantalum coating.
This cursory investigation was inadequate for thoroughly evaluating plasma spray coatings. All the commercially available coatings tested reacted with plutonium, suggesting that noncommercial coatings, such as $\mathrm{Er}_{2} \mathrm{O}_{3}$ or $\mathrm{Y}_{2} \mathrm{O}_{3}$ coatings, would have to be developed. This would require further development and testing to evaluate the adhesion of the coating to the substrate. In addition, some large pores (up to $0.002 \mathrm{in}$.) in the plasma spray coatings could produce surface imperfections and increase the difficulty of removing the part. This is especially true when the imperfections are on surfaces parallel to the direction of die separation, such as around the waist. In view of other successful types (such as release coatings), work on plasma-sprayed coatings was dropped.

\section{Low-Density Coatings}

Testing was also done on alternatively deposited coatings supplied by the Product Integrity and Surveillance group. Because they were designed to serve as insulating coatings, they were generally thicker than those previously supplied. The coatings were deposited on round-bottom $\mathrm{H}-13$ tool steel crucibles. Table 3 summarizes the coating data. Several qualification tests were made, including thermalcycling and long-term compatibility tests.

Separate crucibles, instrumented with thermocouples, were also coated to determine their relative thermal conductivities. The configuration of these tests is

TABLE 3. Coatings Data

\begin{tabular}{|c|c|c|c|c|}
\hline \multirow{2}{*}{$\begin{array}{c}\text { Coating } \\
\text { Composition } \\
(\text { wt } \%)\end{array}$} & \multicolumn{4}{|c|}{ Thickness } \\
\hline & $\begin{array}{l}\text { Number } \\
\text { Supplied }\end{array}$ & $\begin{array}{l}\text { Range } \\
\text { (mils) }\end{array}$ & $\begin{array}{c}\text { Average } \\
\text { (mils) }\end{array}$ & $\begin{array}{c}\text { Porosity } \\
(\%) \\
\end{array}$ \\
\hline $\begin{array}{l}25 \mathrm{CaF}_{2} \\
\quad+70 \mathrm{Er}_{2} \mathrm{O}_{3} \\
\quad+5 \mathrm{SiO}_{2}\end{array}$ & 6 & $6.80-8.80$ & 8.05 & 40 \\
\hline $\begin{array}{l}40 \mathrm{SiO}_{2} \\
\quad+60 \mathrm{Er}_{2} \mathrm{O}_{3}\end{array}$ & 7 & $4.20-6.70$ & 5.71 & 40 \\
\hline $100 \mathrm{Er}_{2} \mathrm{O}_{3}$ & 6 & $2.30-2.80$ & 2.47 & 60 \\
\hline $100 \mathrm{Er}_{2} \mathrm{O}_{3}$ & 6 & $0.18-0.30$ & 0.23 & 15 \\
\hline
\end{tabular}




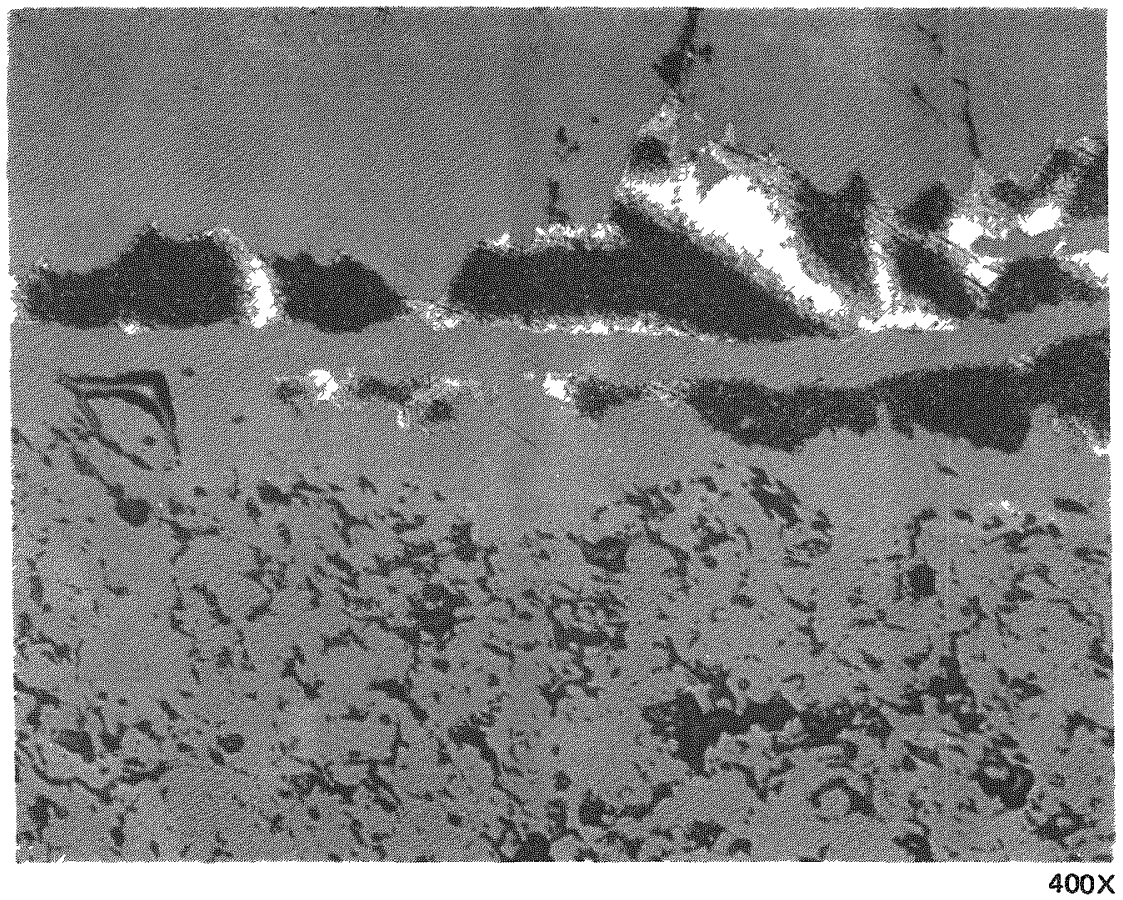

FIGURE 22 Cross Section of $\mathrm{ZrO}_{2}$ - Plutonum Interface Unetched

FIGURE 23 Cross Section of $\mathrm{CaO} \cdot \mathrm{ZrO}_{2}$ - Plutonum Interface Unetched

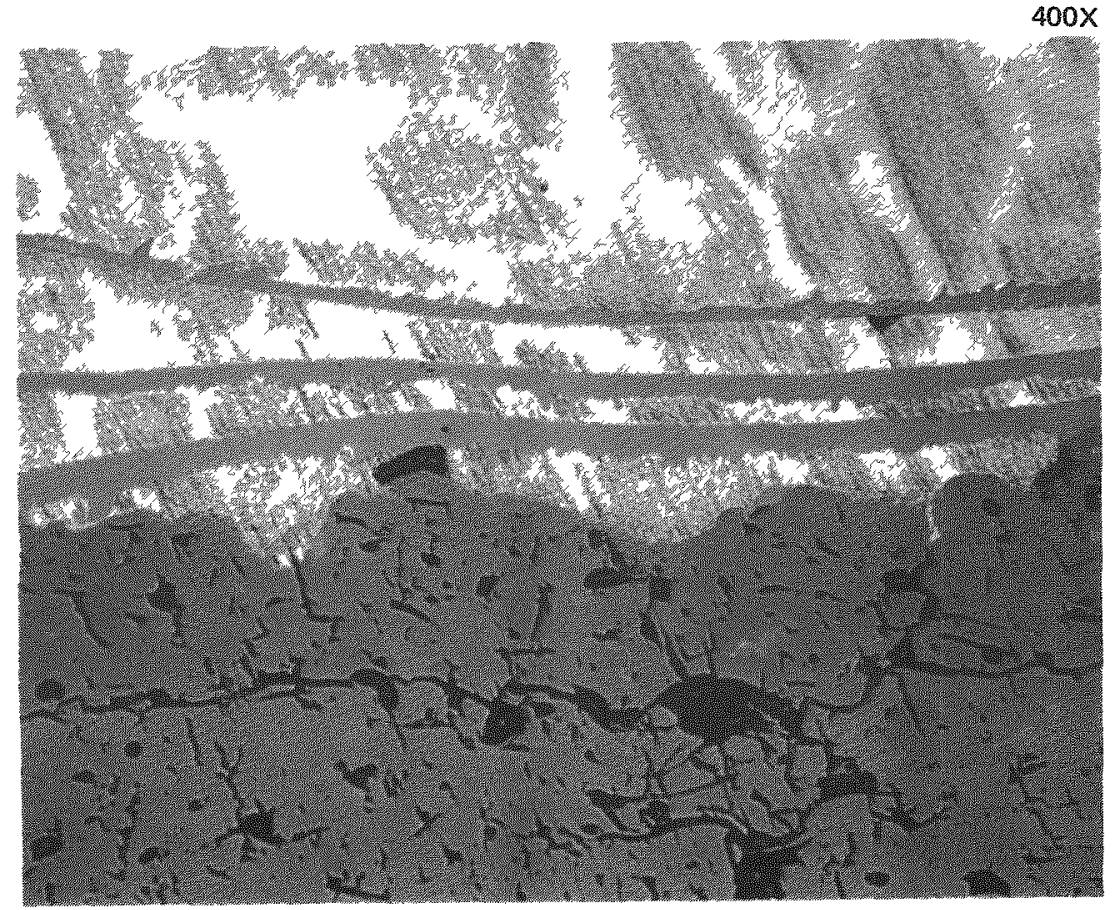


RFP-4162

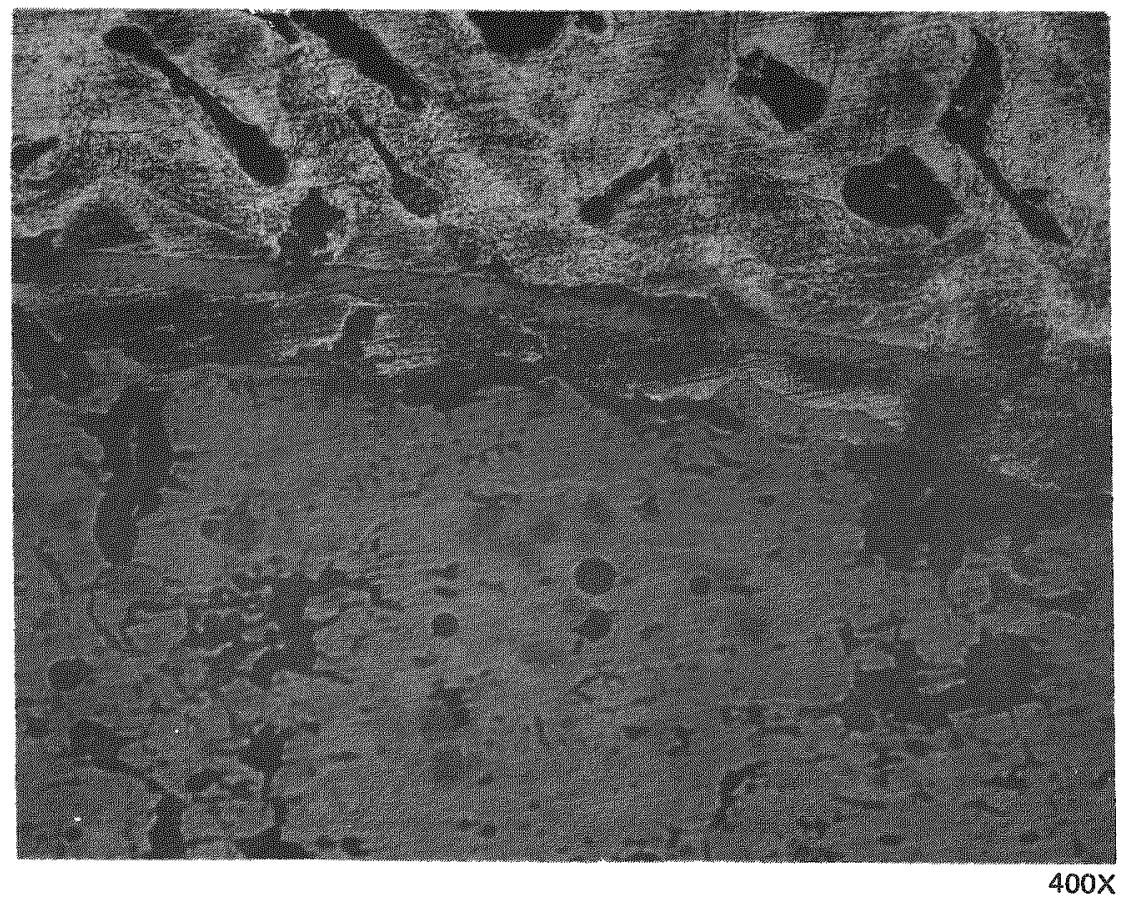

FIGURE 24. Cross Section of $\mathrm{MgO} \cdot \mathrm{ZrO}_{2}$ - Plutonium Interface Unetched

FIGURE 25. Cross Section of $\mathrm{MgO} \cdot \mathrm{ZrO}_{2}+\mathrm{Ni} / \mathrm{Cr}$

Transition Layer - Plutonium Interface Unetched

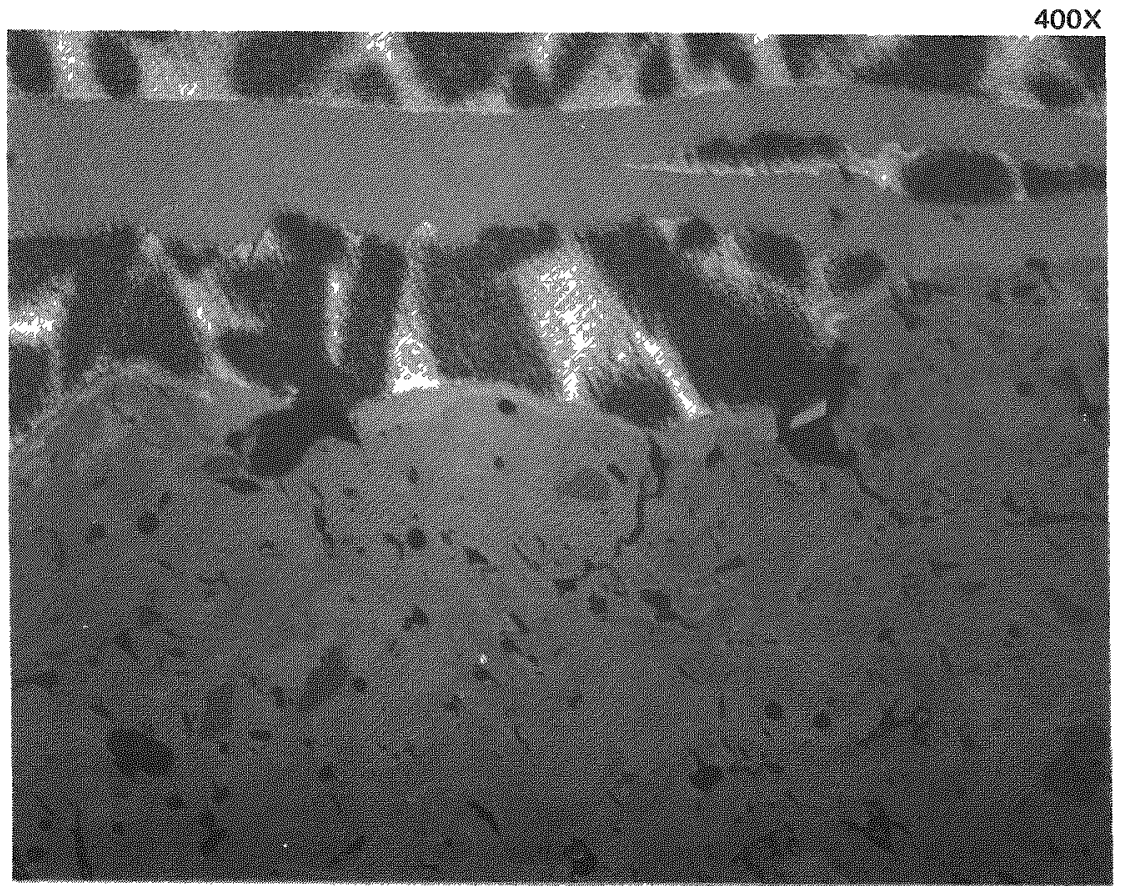




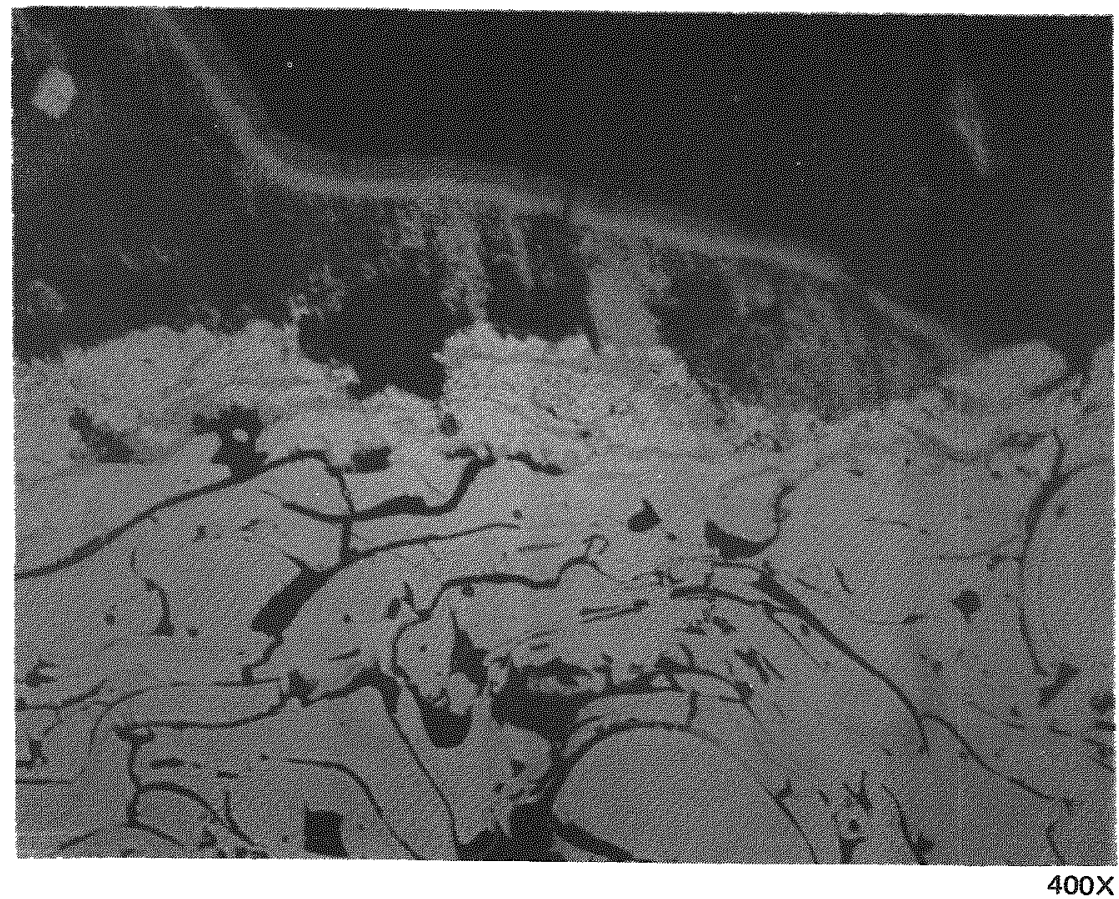

FIGURE 26 Cross Section of $\mathrm{Cr}_{2} \mathrm{C}_{3}$ - Plutonium Interface Unetched

FIGURE 27 Cross Section of Tantalum Coating Unetched

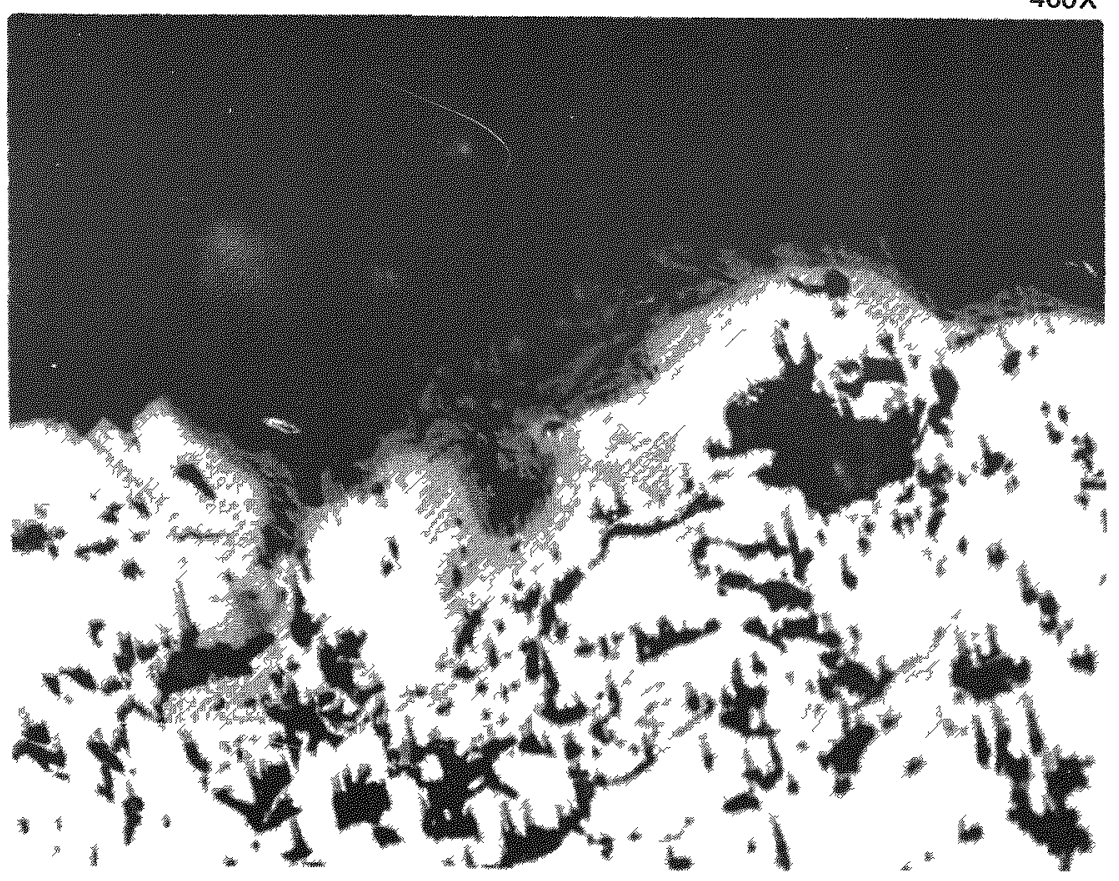




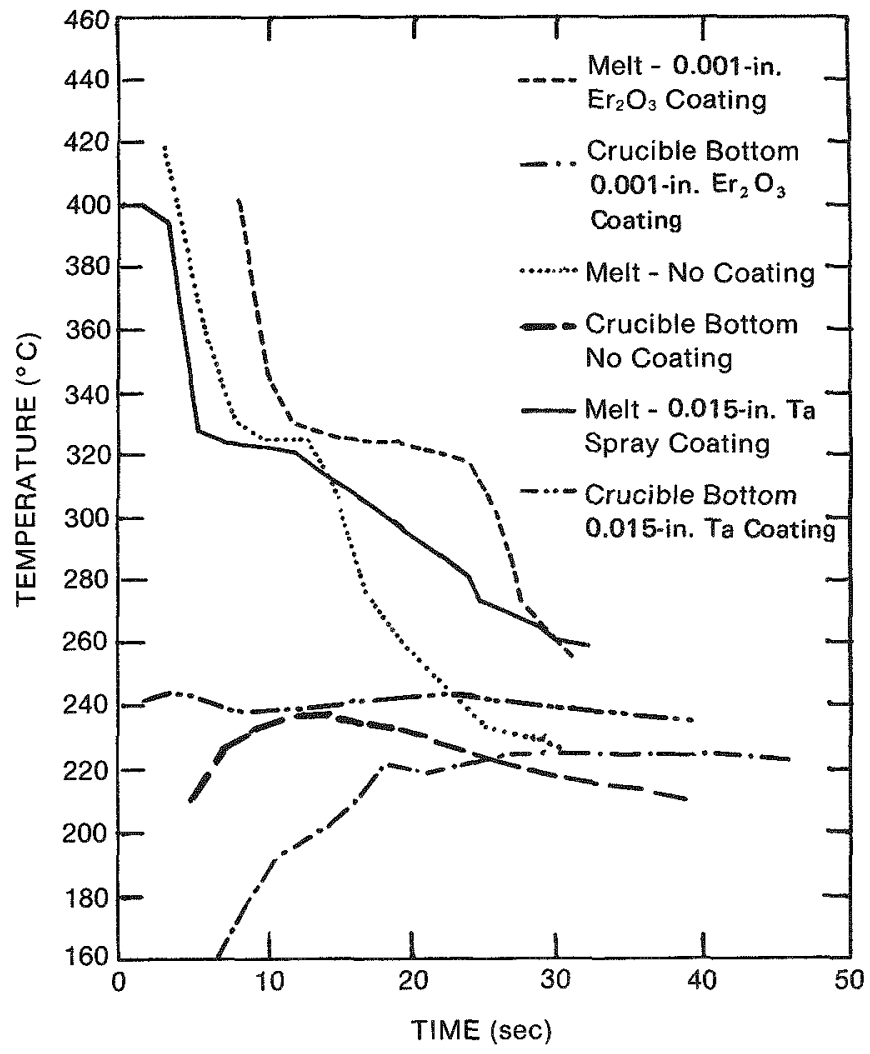

FIGURE 28. Results of Lead Solidification for an Uncoated Crucible, 0.001-in. LowDensity $\mathrm{Er}_{2} \mathrm{O}_{3}$, and Plasma-Sprayed Tantalum

shown in Figure 14. Pertinent data are given in Table 4.

All the coatings survived the 10-cycle thermalcycling test between room temperature and $600^{\circ} \mathrm{C}$.

TABLE 4. Coatings for Conductivity Tests

\begin{tabular}{lcc}
\multicolumn{1}{c}{$\begin{array}{c}\text { Coating } \\
\text { Composition } \\
\text { (wt \%) }\end{array}$} & & $\begin{array}{c}\text { Thickness } \\
\text { (mils) }\end{array}$ \\
$25 \mathrm{CaF}_{2}+70 \mathrm{Er}_{2} \mathrm{O}_{3}+5 \mathrm{SiO}_{2}$ & & 9.0 \\
$25 \mathrm{CaF}_{2}+70 \mathrm{Er}_{2} \mathrm{O}_{3}+5 \mathrm{SiO}_{2}$ & & 8.0 \\
$40 \mathrm{SiO}_{2}+50 \mathrm{Er}_{2} \mathrm{O}_{3}$ & & 4.0 \\
$40 \mathrm{SiO}_{2}+60 \mathrm{Er}_{2} \mathrm{O}_{3}$ & 7.0 \\
$100 \mathrm{Er}_{2} \mathrm{O}_{3}$ & 0.2 \\
$100 \mathrm{Er}_{2} \mathrm{O}_{3}$ & 0.2 \\
$100 \mathrm{Er}_{2} \mathrm{O}_{3}$ & 4.0
\end{tabular}

\section{Porosity}

(\%)

40

40

40

40

25

15

60

Microcracks in the $\mathrm{SiO}_{2}+\mathrm{Er}_{2} \mathrm{O}_{3}$ coating became slightly more prominent, but no spalling resulted. Compatibility testing was done at $1000^{\circ} \mathrm{C}$, and the results are summarized in Table 5. Both the 0.0023inch $\mathrm{Er}_{2} \mathrm{O}_{3}$ coating and the $\mathrm{CaF}_{2}+\mathrm{SiO}_{2}+\mathrm{Er}_{2} \mathrm{O}_{3}$ coating survived 48 hours at $1000^{\circ} \mathrm{C}$ with no apparent penetration by molten plutonium. These rather cursory tests suggest that the $\mathrm{Er}_{2} \mathrm{O}_{3}$ and the $\mathrm{CaF}_{2}+\mathrm{SiO}_{2}+\mathrm{Er}_{2} \mathrm{O}_{3}$ may have potential use as insulating coatings. Further testing is necessary, however.

Results from the lead solidification tests are summarized in Table 6. One test with the $\mathrm{SiO}_{2}+\mathrm{Er}_{2} \mathrm{O}_{3}$ coating was rerun because the thermocouple was not properly immersed in the lead, causing an inconclusive cooling curve. In the course of these tests, some duplicate tests resulted in slightly different normalized thermal arrest values with the same coatings. These differences are probably related to variations in pouring temperature of the lead. A higher pouring temperature would impart more total heat to the system and result in a slightly longer normalized thermal arrest value for a given weight. Included in this table are tests from $\mathrm{Y}_{2} \mathrm{O}_{3}$ applied as the nitrate. In this case, the $\mathrm{Y}\left(\mathrm{NO}_{3}\right)_{3} \cdot 6 \mathrm{H}_{2} \mathrm{O}$ is dissolved in

TABLE 5. Coating Compatibility Tests at $1000^{\circ} \mathrm{C}$

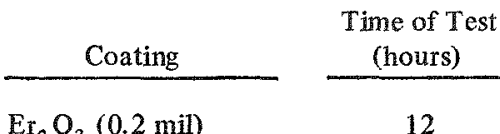

12

$\mathrm{Er}_{2} \mathrm{O}_{3}(0.2 \mathrm{mil})$

$\mathrm{Er}_{2} \mathrm{O}_{3}(2.3 \mathrm{mil})$

$\mathrm{Er}_{2} \mathrm{O}_{3}(2.3 \mathrm{mil})$

$\mathrm{SiO}_{2}+\mathrm{Er}_{2} \mathrm{O}_{3}$

24

24

24

48

24

$\mathrm{CaF}_{2}+\mathrm{SiO}_{2}+\mathrm{Er}_{2} \mathrm{O}_{3}$

24

$\mathrm{CaF}_{2}+\mathrm{SiO}_{2}+\mathrm{Er}_{2} \mathrm{O}_{3}$

\section{Results \\ Metal stuck--loosened after three or four raps on box floor \\ Coating failed--metal ran out}

Metal loose in crucible

Metal loose in crucible

Metal stuck--loose after two raps on box floor; coating came off

Metal loose in crucible (coating may have broken loose)

Metal loose in crucible 
TABLE 6. Lead Tests on Insulaitng Coatings

\begin{tabular}{|c|c|c|c|}
\hline Coating & $\begin{array}{c}\text { Thickness } \\
\text { (mils) }\end{array}$ & $\begin{array}{c}\text { Porosity } \\
(\%) \\
\end{array}$ & $\begin{array}{c}\text { Average } \\
\text { Normalized } \\
\text { Length } \\
\text { (in.) } \\
\end{array}$ \\
\hline $\begin{array}{l}\mathrm{Er}_{2} \mathrm{O}_{3} \\
\mathrm{Er}_{2} \mathrm{O}_{3}+\mathrm{ZrO}_{2} \text { wash } \\
\mathrm{Er}_{2} \mathrm{O}_{3} \\
\mathrm{Er}_{2} \mathrm{O}_{3} \\
\mathrm{Er}_{2} \mathrm{O}_{3}\end{array}$ & $\begin{array}{l}0.2 \\
0.2 \\
0.2 \\
4.0 \\
4.0\end{array}$ & $\begin{array}{l}15 \\
15 \\
25 \\
60 \\
60\end{array}$ & $\begin{array}{l}0.55 \\
0.52 \\
0.96 \\
7.32 \\
7.63\end{array}$ \\
\hline $\begin{array}{l}\mathrm{SiO}_{2}+\mathrm{Er}_{2} \mathrm{O}_{3} \\
\mathrm{SiO}_{2}+\mathrm{Er}_{2} \mathrm{O}_{3} \\
\mathrm{SiO}_{2}+\mathrm{Er}_{2} \mathrm{O}_{3}\end{array}$ & $\begin{array}{l}4 \\
7 \\
7\end{array}$ & $\begin{array}{l}- \\
- \\
-\end{array}$ & $\begin{array}{c}8.56 \\
5.83^{*} \\
13.85^{*} *\end{array}$ \\
\hline $\begin{array}{l}\mathrm{CaF}_{2}+\mathrm{SiO}_{2}+\mathrm{Er}_{2} \mathrm{O}_{3} \\
\mathrm{CaF}_{2}+\mathrm{SiO}_{2}+\mathrm{Er}_{2} \mathrm{O}_{3}\end{array}$ & $\begin{array}{l}8 \\
9\end{array}$ & $\begin{array}{l}- \\
-\end{array}$ & $\begin{array}{l}8.32 \\
9.36\end{array}$ \\
\hline $\begin{array}{l}\mathrm{Y}_{2} \mathrm{O}_{3} \text { (nitrate) } \\
\mathrm{Y}_{2} \mathrm{O}_{3} \text { (nitrate) }\end{array}$ & $\begin{array}{l}7 \\
7\end{array}$ & - & $\begin{array}{l}10.87 \\
12.20\end{array}$ \\
\hline $\begin{array}{l}\text { * Misplaced thermoco } \\
\text { * Rerun. }\end{array}$ & & & \\
\hline
\end{tabular}

ethyl alcohol and sprayed onto the crucible, which is heated to about $150-200{ }^{\circ} \mathrm{C}$. Following this, the crucible is heated to about $400^{\circ} \mathrm{C}$ to drive off the $\mathrm{NO}_{2}$, leaving the $\mathrm{Y}_{2} \mathrm{O}_{3}$ coating behind. From the data in Table 6 , the following conclusions can be drawn:

1. Thicker coatings are more insulating than thinner coatings. This is as expected.

2. Low-density coatings are more insulating than high-density coatings for the same thickness. This is also as expected.

3. The $\mathrm{SiO}_{2}+\mathrm{Er}_{2} \mathrm{O}_{3}$ coating is a better insulator than the $\mathrm{CaF}_{2}+\mathrm{SiO}_{2}+\mathrm{Er}_{2} \mathrm{O}_{3}$ coating.

4. A thin $\mathrm{ZrO}_{2}$ wash over a 0.0002-inch $\mathrm{Er}_{2} \mathrm{O}_{3}$ coating provides little or no additional insulating value. No benefit is derived from a very thin coating.

5. Pure $\mathrm{Er}_{2} \mathrm{O}_{3}$ is better than $\mathrm{CaF}_{2}+\mathrm{SiO}_{2}+\mathrm{Er}_{2} \mathrm{O}_{3}$ in an insulator, but not as good as $\mathrm{SiO}_{2}+\mathrm{Er}_{2} \mathrm{O}_{3}$, or $\mathrm{Y}_{2} \mathrm{O}_{3}$ applied as the nitrate. No reason can be given at the present time for these differences.

\section{Release Coatings}

Difficulties encountered in ex tracting a casting from the die prompted the use of a release coating on the die. The purpose of this coating is to be a nonadherent wash, which readily separates from the $\mathrm{Er}_{2} \mathrm{O}_{3}$ coating and allows easy removal of the part.

The first release coating attempted was a $\mathrm{ZrO}_{2}$ powder suspended in ethyl alcohol. The $\mathrm{ZrO}_{2}$ powder was the same powder used in uranium casting operations and contains about $10 \% \mathrm{Y}_{2} \mathrm{O}_{3}$. Initial application was made by brushing the suspension onto the die, which was previously heated to about $125^{\circ} \mathrm{C}$. Some runoff and streaking were experienced due to uneven distribution of the wash. A dramatic improvement was experienced in the force required to remove the part from the die. Streaks in the coating transferred to the surface of the casting.

Later techniques involved the use of an air brush to spray the wash coat onto the die. This worked well and resulted in a very smooth, even distribution with no sacrifice in the releasing ability of the wash. However, numerous small gas bubbles appeared on the surface of the casting. This wash coating was then abandoned in favor of one containing $\mathrm{Y}_{2} \mathrm{O}_{3}+$ carboxymethylcellulose (CMC). This was easy to apply, produced a smooth coating, and contributed no defects to the casting. After applying the coating, the dies are heated to about $400{ }^{\circ} \mathrm{C}$ under vacuum to decompose and remove the $\mathrm{CMC}$.

Subsequent work revealed that the $\mathrm{CMC}$ binder may be undesirable because (1) it has a high burnoff temperature $\left(>500^{\circ} \mathrm{C}\right)$, and (2) the water used as a carrier could be a hazard when introduced into a system involving plutonium. To resolve these problems, other binders were investigated as alternatives. ${ }^{5}$ The two best alternatives were Rhoplox B60A (a Rohm and Haas trademark for aqueous dispersions of acrylic polymers) and Ethocel (Dow Chemical trademark for ethylcellulose resin). Rhoplox uses water as a carrier, while Ethocel uses 1,1,1-trichloroethane as a carrier.

Both Rhoplox B60A and Ethocel had low thermal decomposition temperatures $\left(300-400^{\circ} \mathrm{C}\right)$, produced good surface quality, and had good adhesion. Although the Rhoplox B60A does not eliminate 
water from the system, the 1,1,1-trichloroethane reacts unpredictably with aluminum or galvanized parts. This potential safety hazard effectively ruled out this material, and the Rhoplox B60A became the binder of choice for the $\mathrm{Y}_{2} \mathrm{O}_{3}$ insulating coating.

In view of the work described above, the release coating should also provide insulating value to the dies and aid in minimizing cold shuts.

\section{CONCLUSIONS}

1. For a 1/8-inch gate, the incoming metal loses about $17 \%$ of its velocity because of the surface roughness of a coating. This is not considered excessive.

2. An insultating coating allows use of cooler dies, producing a subsequent refinement in grain size.

3. Low-density coatings provide better insulating capabilities than high-density coatings. With a porosity of $50 \%$, the thermal conductivity of a porous coating is reduced to about $1 / 80$ of that for $100 \%$ dense material.

4. $\mathrm{CaO}, \mathrm{Er}_{2} \mathrm{O}_{3}$, and $\mathrm{ZrO}_{2}$ have similar insulating capabilities.

5. Thick coatings provide more insulating capability than thin coatings.

6. $\mathrm{Er}_{2} \mathrm{O}_{3}$ and $\mathrm{Y}_{2} \mathrm{O}_{3}$ have similar insulating capabilities with $\mathrm{Y}_{2} \mathrm{O}_{3}$ being slightly better.

7. The time to solidify microspheres increases with radius.

8. Microspheres larger than $0.080 \mathrm{~cm}$ require more than 0.31 second to solidify when the die temperature is at $300^{\circ} \mathrm{C}$, and should not produce cold shots.

9. Formation of smaller microspheres can be prevented by increasing the die temperature or reducing metal turbulence.
10. The time required to solidify microspheres can be increased about 20 times by using an insulating coating.

11. All commercially available plasma-sprayed ceramics showed reactions with plutonium at $750^{\circ} \mathrm{C}$.

12. Some insulating capability was observed with a 0.015-inch-thick plasma-sprayed tantalum coating.

13. A thin $\mathrm{ZrO}_{2}$ wash over a 0.0002 -inch $(0.2$ mil) $\mathrm{Er}_{2} \mathrm{O}_{3}$ coating provides little or no additional insulating value.

14. Release coatings were developed to allow easy removal of the part from the die. These coatings also provide insulating capabilities for the die.

\section{REFERENCES}

1. H. R. Gardner, Physical and Mechanical Metallurgy Studies on Delta Stabilized Plutonium-Gallium Alloys, BNWL-13, Batelle-Northwest Laboratories, Richland, WA, April 1965.

2. G. H. Geiger and D. R. Poirier, Transport Phenomena in Metallurgy, p 80, AddisonWesley Publishing Company, Reading, MA.

3. R. G. Deissler and C. S. Eian, NACA, RM E52C05 (1952), referenced in G. H. Geiger and D. R. Poirier, Transport Phenomena in Metallurgy, p 201, Addison-Wesley Publishing Company, Reading, MA.

4. W. A. Pennington, "Definitions Relating to Metals and Metalworking," Metals Handbook, 8th Edition, I, pp 1-41, American Society for Metals, 1961.

5. L. M. Bagaasen and G. S. Fenner, Release Coatings for Plutonium Die Casting, RFP-4232, Rockwell International, Rocky Flats Plant, Golden, CO, May 1988. 